\title{
Numerical modeling and experimental investigation on the effect of low-salinity water flooding for enhanced oil recovery in carbonate reservoirs
}

\author{
Erfan Hosseini $^{1}$. Mohammad Sarmadivaleh ${ }^{2} \cdot$ Dana Mohammadnazar $^{3}$
}

Received: 23 June 2020 / Accepted: 14 December 2020 / Published online: 23 January 2021

(c) The Author(s) 2021

\begin{abstract}
Numerous studies concluded that water injection with modified ionic content/salinity in sandstones would enhance the oil recovery factor due to some mechanisms. However, the effects of smart water on carbonated formations are still indeterminate due to a lack of experimental investigations and researches. This study investigates the effects of low-salinity (Low Sal) solutions and its ionic content on interfacial tension (IFT) reduction in one of the southwestern Iranian carbonated reservoirs. A set of organized tests are designed and performed to find each ion's effects and total dissolved solids (TDS) on the candidate carbonated reservoir. A sequence of wettability and IFT (at reservoir temperature) tests are performed to observe the effects of controlling ions (sulfate, magnesium, calcium, and sodium) and different salinities on the main mechanisms (i.e., wettability alteration and IFT reduction). All IFT tests are performed at reservoir temperature $\left(198{ }^{\circ} \mathrm{F}\right)$ to minimize the difference between reservoir and laboratory-observed alterations. In this paper, the effects of four different ions $\left(\mathrm{SO}_{4}{ }^{2-}, \mathrm{Ca}^{2+}, \mathrm{Mg}^{2+}, \mathrm{Na}^{+}\right)$and total salinity $\mathrm{TDS}(40,000,20,000,5000 \mathrm{ppm})$ are investigated. From all obtained results, the best two conditions are applied in core flooding tests to obtain the relative permeability alterations using unsteady-state methods and Cydarex software. The final part is the simulation of the whole process using the Schlumberger Eclipse black oil simulator (E100, Ver. 2010) on the candidate reservoir sector. To conclude, at Low Sal (i.e., 5000 ppm), the sulfate ion increases sulfate concentration lower IFT, while in higher salinities, increasing sulfate ion increases IFT. Also, increasing calcium concentration at high TDS (i.e., 40,000 ppm) decreases the amount of wettability alteration. In comparison, in lower TDS values (20,000 and $5000 \mathrm{ppm})$, calcium shows a positive effect, and its concentration enhanced the alteration process. Using Low Sal solutions at water cut equal or below $10 \%$ lowers recovery rate during simulations while lowering the ultimate recovery of less than $5 \%$.
\end{abstract}

Keywords Smart water injection · Oil recovery factor · Interfacial tension (IFT) · Total dissolved solids (TDS) · Wettability $\cdot$ Core flooding

Erfan Hosseini

e.hosseini19@gmail.com

1 Department of Petroleum Engineering, Sarvak Azar Engineering, and Development (SAED) Company, Oil Industries Engineering and Construction (OIEC) Group, Tehran, Iran

2 Department of Petroleum Engineering, Curtin University, Perth, Australia

3 Department of Polymer Chemistry, Islamic Azad University, Shahreza, Iran

\section{Introduction}

Recovery is at the heart of oil production from underground reservoirs. If the average worldwide recovery factor from hydrocarbon reservoirs can be increased beyond current limits, it will alleviate several global energy supplies. This challenge becomes an opportunity for advanced secondary and enhanced oil recovery (EOR) technologies to mitigate the demand-supply balance. EOR is capital and resourceintensive and expensive, primarily due to high injecting costs. Realization of EOR potential can only be achieved through long-term commitments, both in the capital and human resources, a vision to strive toward ultimate oil recovery instead of immediate oil recovery, research and 
development, and a willingness to take risks. While EOR technologies have grown over the years, significant challenges remain (Kokal and Al-Kaabi, 2010). As more and more, Low Sal experiments were conducted on mineralogy, clay content continued to be emphasized, but a comprehensive and predictive mechanistic model remained unavailable. Many recent experiments have been conducted in the candidate reservoir core because Low Sal response remains difficult to forecast. Researchers observed dramatic results with clay-rich sandstone reservoir cores and, for the first time, in almost clay free cores. Zhang et al. (2006) reported an increased recovery in the tertiary mode by reducing reservoir brine salinity 20 times. Two consolidated reservoir sandstone cores were used. X-ray diffraction indicated that each of the cores was rich in Chert and Kaolinite. Two different crudes and mineral oil were used. Almost $70 \%$ of incremental oil recovery was achieved in the secondary mode. Both the high and Low Sal secondary floods were conducted in the same core. Tertiary recovery was also quite large: $25 \%$ incremental recovery in the best case. The recovery was achieved slowly, taking more than ten injected pore volumes. In several cases, the $\mathrm{pH}$ fell upon Low Sal brine injection, contrary to other researcher's observations. Pressure drop was closely tied to incremental recovery. In all cases where significant incremental recovery was achieved, pressure drop increased significantly and then fell gradually. Pu et al. (2008b, a) proposed that dolomite crystals play an important role in the Low Sal recovery mechanism. Some of the dolomite crystals become mixed-wet as they contacted the oil phase during aging. During the Low Sal flood, the dolomite crystals may detach from the pore walls releasing oil from the rock surface. The detached dolomite crystals will then reside at the crude oil-brine interface, increasing resistance to brine flow at the interface, delaying snap-off at pore-throats, and preventing the collapse of oil lamella. Agbalaka et al. (2009) conducted water flood experiments to study the recovery benefit of using Low Sal brine. Researchers used Berea sandstone and Milne Point Unit cores. 4, 2 , and $1 \% \mathrm{NaCl}$ brine and Trans Alaskan Pipeline System (TAPS) crude oil and refined decane spiked with TAPS crude were used. Incremental oil was recovered in tertiary mode by switching from 4 to $2 \%$ to $1 \% \mathrm{NaCl}$ brine. Improved recovery was also achieved by injecting Low Sal brine in the secondary mode. Pressure drop data were unpublished. Researchers measured wettability with the Amott method and found an increase in the degree of water-wetness with a decrease in $\mathrm{NaCl}$ concentration. Injection of Low Sal brine has improved water flood recovery in numerous laboratory and field experiments. Researchers' consensus is that injecting Low Sal brine creates a wetting state more favorable to oil recovery. Wettability affects the microscopic distribution and flow of oil and water in porous media and residual oil saturation. The mechanisms responsible for this wettability alteration are not clear. Tang and Morrow hypothesized heavy polar components in the crude oil adsorb onto fine particles along the pore walls and that these mixed-wet fines are stripped by Low Sal brine. Pu et al. (2008b, a) proposed that mix-wet dolomite crystals detach from the pore walls releasing oil from the rock surface during a Low Sal flood. The detached dolomite crystals will then reside at the crude oil-brine interface, increasing resistance to brine flow at the interface, delaying snap-off at pore-throats, and preventing the collapse of oil lamella. Mechanisms not involving wettability alteration have also been suggested. Hosseini et al. (2020) experimentally investigated Low Sal water to alter wettability in carbonate oil reservoirs. Their work showed that the injection of Low Sal water, followed by highersalinity water, would lead to greater wettability alteration and total recovery. So it is better to use Low Sal water as the secondary recovery process. Considering the significance of these effective parameters and the fact that this paper is aimed to investigate the applicability of Low Sal in one of the southwestern Iranian reservoirs, from the parameters mentioned before, the effects of divalent ions (sulfate, calcium, and magnesium) and univalent cation (sodium) are studied to investigate the applicability of smart water injection to one of the southwestern Iranian carbonate reservoirs. In details, the following objectives are meant to be achieved:

- Investigation of crude/Low Sal interaction during Low Sal EOR

- Study of Crude/Low Sal interactions in contact with reservoir rock (wettability modifications)

- Study of effective and active mechanisms in carbonate reservoirs

- Analysis of applying smart water EOR and its efficiency to one of the Iranian carbonate reservoirs (Ahvaz Asmari is chosen as the candidate field in this study).

- Choosing the best condition of applying smart water process by using commercial simulators

\section{Methodology and experiments}

\section{Designing experiments}

Design-Expert (Version 8) is used in this study. RSM methodology is appropriate for designing IFT and wettability (contact angle) tests to lower the risk of performing unanalyzable experiments and increase the chance of suitable conclusions. Response surface methodology (RSM) consists of a group of mathematical and statistical techniques used in the development of a good functional relationship between a response of interest, $y$, and several associated control (or input) variables denoted by (X1, X2, .., Xk). In general, 
such a relationship is unknown but can be approximated by a low-degree polynomial model of the form:

$y=f^{\prime}(x) \beta+E$

where $\mathrm{x}=(X, X 2, \ldots, X K), \mathrm{f}^{\prime}(x)$ is a vector function of $\mathrm{p}$ elements that consists of powers and cross-products of powers of $(X 1, X 2, \ldots, X k)$ up to a certain degree denoted by $d(\geq 1), \beta$ is a vector of $\mathrm{p}$ unknown constant coefficients referred to as parameters. $\mathrm{E}$ is a random experimental error assumed to have a zero mean. This is conditioned on the belief that the proposed polynomial model provides an adequate representation of the response (Alben 2002). A basic design is prepared for solutions with 40,000 ppm salinity (Table 1). 20,000 and 5,000 ppm solutions are obtained by diluting 40,000 ppm ones to make each relative ion salinity $\left(\mathrm{C}_{\mathrm{ion}} / \mathrm{C}_{\text {total }}\right)$ constants for a specific solution and its dilutions $(20,000,5,000 \mathrm{ppm})$.

According to Table 1, each TDS series consists of 12 different ionic content conditions. Three different TDS values (i.e., 40,000, 20,000, and $5000 \mathrm{ppm}$ ) are tested, which means that a total of 36 different shapes may be evaluated during IFT and wettability tests.

\section{Sample preparation}

\section{Rock samples}

Reservoir core plugs are prepared using plugging and trimming apparatuses from Vinci Tech. These are gathered from gathered core plugs, rock sections, and free imbibition cores (length below $4 \mathrm{~cm}$ ) are prepared using trimming systems. After plugging and trimming, all samples are cleaned in an ultrasonic bath for $30 \mathrm{~min}$. The cleaned samples dried at $95{ }^{\circ} \mathrm{C}$ for $24 \mathrm{~h}$ and stored in silica-gel packs for further usage. To obtain sections and core plugs with the same

Table 1 Experiment design prepared for 40,000 ppm solutions

\begin{tabular}{lrrrr}
\hline Test-ID & $\mathrm{SO}_{4}{ }^{2-}(\mathrm{ppm})$ & $\mathrm{Mg}^{2+}(\mathrm{ppm})$ & $\mathrm{Ca}^{2+}(\mathrm{ppm})$ & $\mathrm{Na}^{+}(\mathrm{ppm})$ \\
\hline 1 & 7439.95 & 7269.86 & 154.00 & 5535.09 \\
2 & 0.00 & 0.00 & 700.00 & 7635.39 \\
3 & $13,391.90$ & 0.00 & 332.35 & 967.46 \\
4 & 9198.48 & 3420.69 & 0.00 & 6386.38 \\
5 & $25,743.00$ & 0.00 & 700.00 & $11,258.14$ \\
6 & 0.00 & 4901.28 & 332.50 & 4458.07 \\
7 & $27,054.35$ & 0.00 & 0.00 & 630.22 \\
8 & 9469.02 & 4033.35 & 700.00 & 6971.27 \\
9 & 0.00 & 9716.00 & 700.00 & 5036.13 \\
10 & $13,845.26$ & 4735.00 & 353.46 & $11,801.85$ \\
11 & 0.00 & $10,211.01$ & 0.00 & 5036.13 \\
12 & 0.00 & 0.00 & 0.00 & $11,801.85$ \\
\hline
\end{tabular}

lithology and property, the following steps are followed to select the needed number of cores and units:

1) Rock samples are gathered from the Asmari reservoir layer.

2) Core plugs are prepared using a plugging machine (with a maximum length of $10 \mathrm{~cm}$ ).

3) Using a trimming machine, sections prepared from plugs (totally 170 thin sections) from which 36 of them with the most closer ones (i.e., ones that seemed to be more similar with bare eyes) are selected wettability tests.

4) From the remaining plugs, 12 core samples with a length below $4 \mathrm{~cm}$ are prepared for free imbibition tests. After porosity/permeability measurements, 7 of them with closer properties (i.e., porosity and permeability) are chosen.

5) Six core plugs with a length of 6-7 $\mathrm{cm}$ are prepared. After porosity and permeability measurements, 2 (with closer porosity and permeability) are selected for core flooding tests.

It is worth mentioning that all selected core plugs are checked (with bare eyes) to decrease the possibility of any vague/fissure existence. Core apparatus provided by Vinci Tech. is used for porosity/permeability measurements. An $\mathrm{XRD}$ test is also performed on some of the rock sections to obtain samples' dominant lithology. More than $95 \%$ of samples are formed of calcite $\left(\mathrm{CaCO}_{3}\right)$ and is carbonated based on the XRD results. In Table 2, the overall data of prepared core plugs for free imbibition and core flooding tests are presented.

\section{Rock samples aging}

Rock sections: each section aged in synthetic reservoir brine for one week. The aging sequence was followed by one month of aging in reservoir crude oil. Prepared units are then used for wettability alterations by four days of aging in smart water solutions. Core plugs are first saturated by reservoir brine followed by two sequences of oil injections. After each oil-flooding sequence, samples are aged in crude oil for two weeks to alter wettability conditions toward more oil-wet conditions. It may be useful to mention that all aging sequences are performed at reservoir temperature $\left(198^{\circ} \mathrm{F}\right)$ and 3000 psi pressure.

\section{Solutions preparation}

Different salts (i.e., $\mathrm{NaCl}, \mathrm{Na}_{2} \mathrm{SO}_{4}, \mathrm{CaCl}_{2}, \mathrm{MgCl}_{2}$, and $\mathrm{Na}_{2} \mathrm{CO}_{3}$ ) purchased from Merck company are used to prepare all solution samples (both synthetic reservoir brine and smart water solutions). To obtain lower TDS versions of smart water samples (i.e., 5000 and 20,000 ppm), dilution

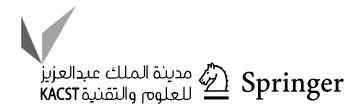


Table 2 Overall properties of prepared core plugs for free imbibition and core flooding tests

\begin{tabular}{llllll}
\hline Test & Plug name & Diameter $(\mathrm{cm})$ & Length $(\mathrm{cm})$ & Porosity $(\%)$ & Permeability $(\mathrm{mD})$ \\
\hline Imbibition & C-1 & 3.76 & 3.34 & 21.47 & 16.788 \\
Imbibition & C-2 & 3.75 & 3.155 & 22.2 & 17.354 \\
Imbibition & C-3 & 3.755 & 3.09 & 21.79 & 17.438 \\
Imbibition & C-4 & 3.745 & 3.165 & 22.48 & 18.056 \\
Imbibition & C-5 & 3.75 & 4.38 & 21.59 & 20.593 \\
Imbibition & C-6 & 3.75 & 3.805 & 21.93 & 22.577 \\
Imbibition & C-7 & 3.775 & 3.22 & 22.18 & 22.986 \\
Flood & CF-1 & 3.805 & 6.92 & 23.74 & 22.714 \\
Flood & CF-2 & 3.75 & 7.38 & 22.91 & 20.932 \\
\hline
\end{tabular}

was applied to the synthesized 40,000 ppm versions. All solutions were stirred for nearly one hour to assure complete dissolution of salts. Prepared solutions are kept in closed bottles (to prevent vaporization) for further use.

\section{Experiments}

\section{Wettability alteration (contact angle)}

Thirty-six different rock sections are used to observe other solutions on the wettability alteration of samples. DSA 100 apparatus from Kruss Co. is used for measuring the contact angle of an oil drop on rock samples in a smart water solution. Rock section (after the aging process) aged in smart water solutions for four days to undergo any possible wettability alterations due to ions or samples TDS. The degree of wettability alteration $\left(\theta_{\text {oilwet }}-\theta_{\text {final }}\right)$ is used as the analyzing parameter to determine approximate ions effects using Design-Expert software.

\section{IFT measurements}

The VIT 700 apparatus purchased from Vinci Tech. is used to perform IFT tests at reservoir temperature. During each of the IFT tests, enough time (nearly $4 \mathrm{~h}$ ) is given to the system to reach equilibrium. All observed IFT values are used as the analyzing parameter in the Design-Expert software.

\section{Free imbibition tests}

As mentioned in the introduction part, from all performed IFT and Wettability alteration tests, six different conditions (two of each TDS category) are elected to be used in free imbibition tests. A free imbibition test is performed using reservoirs brine to compare other sample's results in addition to these six conditions. A simple Amott cell is used as an imbibition cell at reservoir temperature (at $198^{\circ} \mathrm{F}$ ). Oil production (or recovery) is recorded concerning time for different solutions.

\section{Core flooding tests}

The main goal of performing core flooding tests is to gather required data for the simulation process to apply the most suitable conditions observed during previous experiments to a field's sector model. For this reason, the flooding sequence mentioned below is used for each core plug:

(1) Prepared plugs are water flooded (with reservoir brine).

(2) After reaching residual oil saturation, oil flooding is performed on each plug.

(3) Previous oil flooding is followed by water flood again (with reservoir brine). In this step, pressure difference and core plugs, water production, and oil production are recorded to obtain relative permeability values (during water flooding with reservoir brine).

(4) After reaching water flood residual oil saturation, five pore volumes of selected smart water solutions are injected into the core plug (with the rate of $1 \mathrm{PV}$ per hour) to give enough time to the samples to undergo the wettability alteration process.

(5) The wetness alteration sequence is followed by oil flooding.

(6) Previous oil flooding is followed to be smart water flooding. In this step, pressure differences along the core, water, and oil productions are recorded to obtain relative permeability values (for smart water solutions, after the wettability alteration process). A schematic of the core flooding apparatus is shown in Fig. 1.

The main idea behind the above flooding sequence is to remove the first imbibition/drainage hysteresis from relative permeability values. 


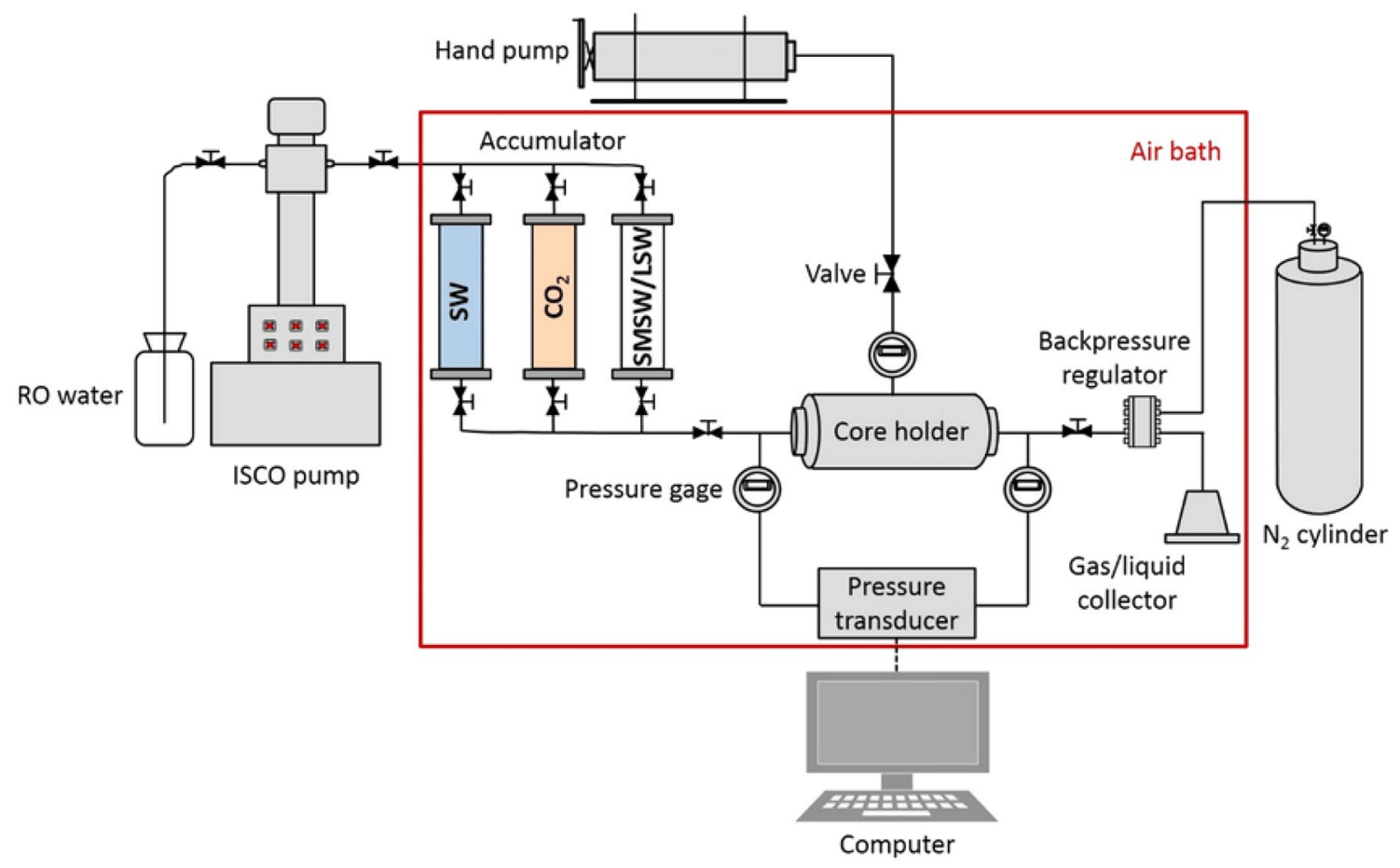

Fig. 1 Schematic of used flooding system for relative permeability evaluation

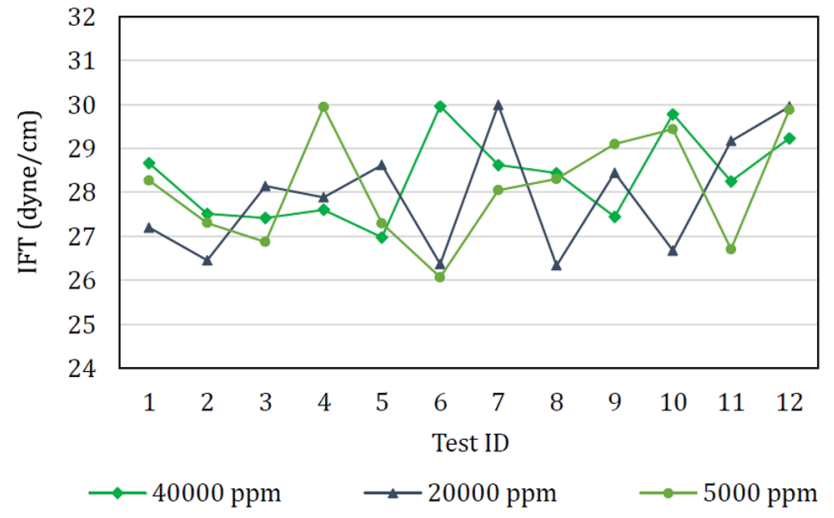

Fig. 2 IFT variation between different test conditions (i.e., 40,000, 20,000, and 5,000 ppm)

\section{Results and discussion}

\section{IFT tests}

All results obtained from the IFT tests are analyzed using Design-Expert software to get any approximation (or relation) between controlling ions concentrations in each TDS with observed IFT between solutions and crude oil. IFT values are shown in Fig. 2.

By further analysis, an approximation of each ion effect on IFT in each TDS was obtained at other ions' average

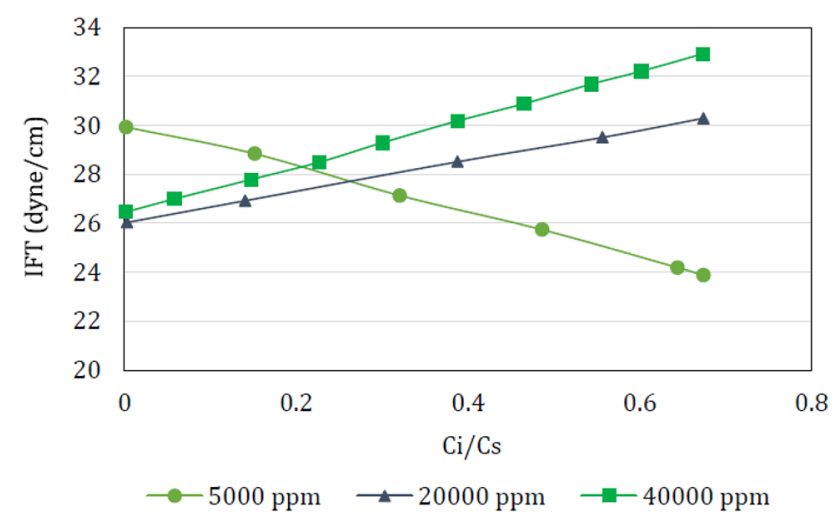

Fig. 3 Effect of sulfate ion on IFT

concentration. Due to the high interactions between ions, a range is identified (minimum and maximum) as the ion effect on IFT values. In Figs. 3, 4, 5 and 6, the impact of all ions for different TDSs is presented.

Among all studied ions, sulfate shows a different trend. In higher-salinity solutions (i.e., 40,000 and 20,000 ppm), increasing sulfate concentration results in higher IFT values. But by dilution (at least to $5000 \mathrm{ppm}$ ), sulfate influence will completely change, and rising sulfate concentration will lower crude/solution observed IFT. Calcium shows no impact on IFT, except that lowering solutions TDS lowers observed IFT, which results from less ion concentration, not the existence of calcium ions. Figure 4 is presented for 


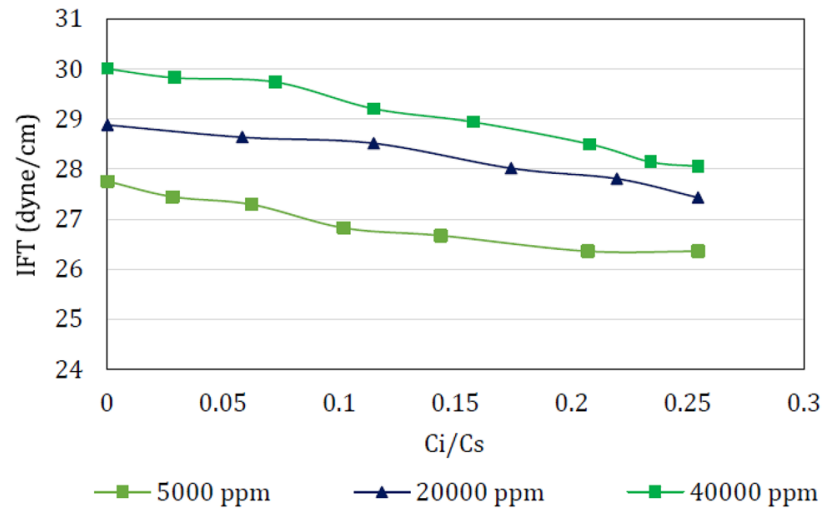

Fig. 4 Effect of magnesium ion on IFT

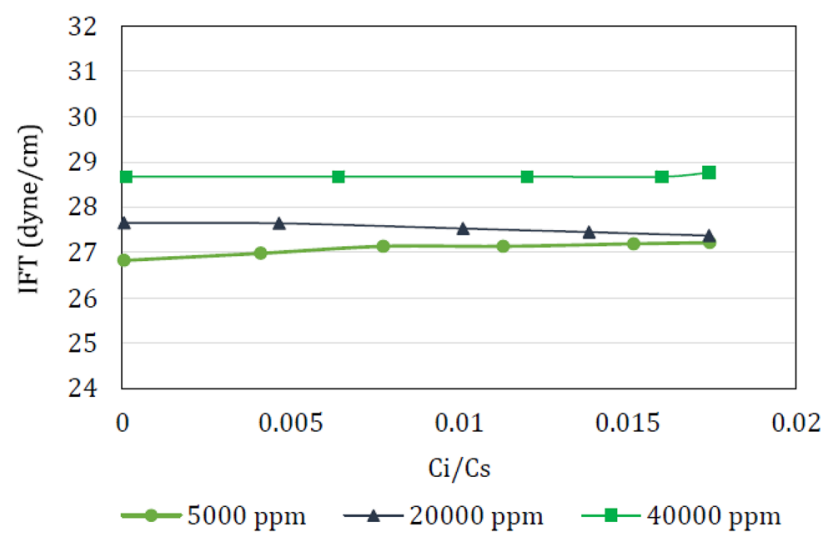

Fig. 5 Effect of calcium ion on IFT

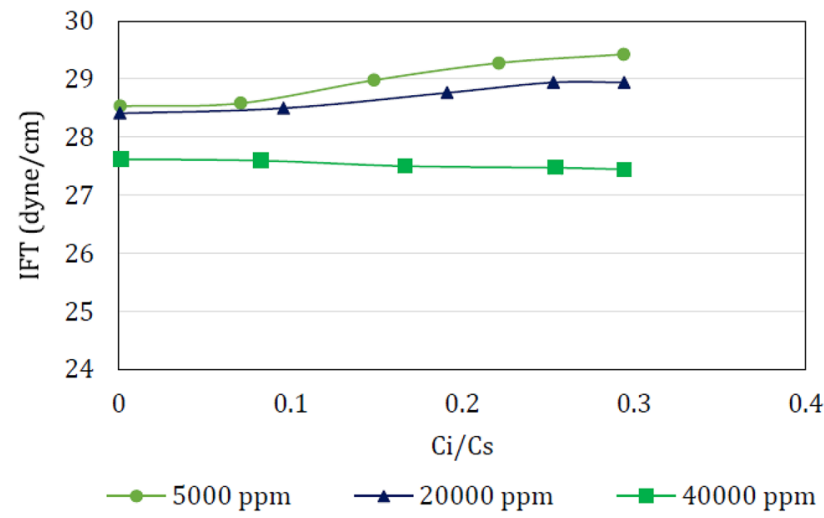

Fig. 6 Effect of sodium ion on IFT

the magnesium effect shows clearly its positive impact on IFT. Increasing magnesium lowers IFT in all TDS values. It must be mentioned that increasing or decreasing solutions TDS does not change magnesium's effect on IFT. Like calcium, vertical differences between curves presented in Fig. 4

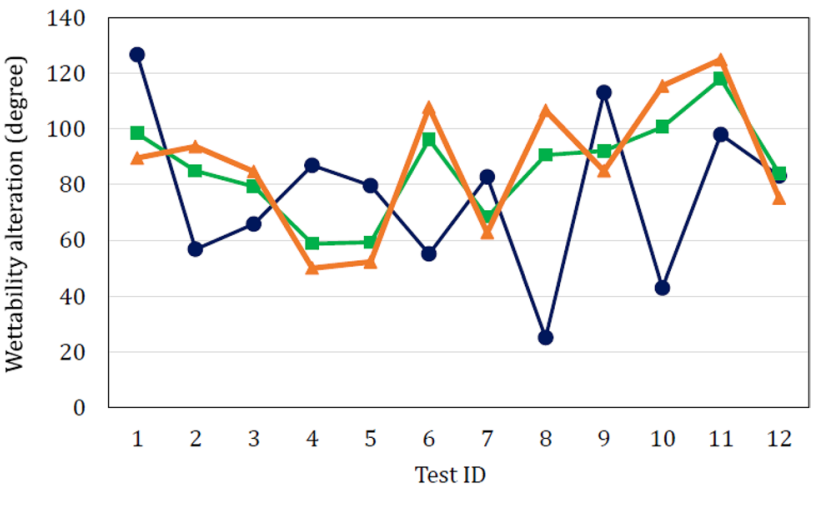

$\rightarrow 40000 \rightarrow-20000 \longrightarrow 5000$

Fig. 7 Contact angle alteration between different test conditions

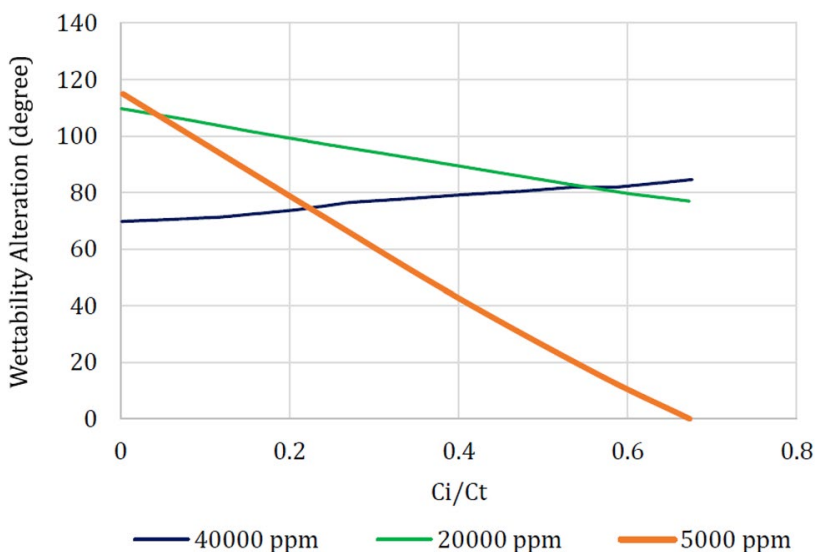

Fig. 8 Effect of sulfate ion on wettability alteration

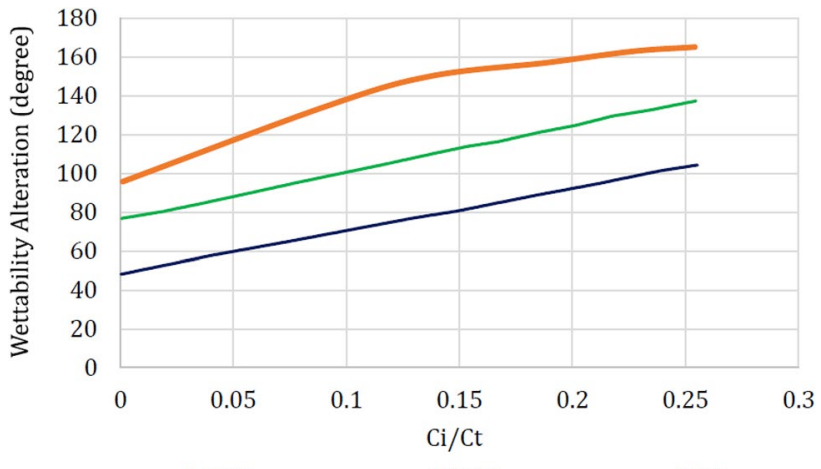

Fig. 9 Effect of magnesium ion on wettability alteration

are due to changes in solutions TDS. At low TDS values, sodium does not affect IFT (just like calcium). In higher TDS values, increasing sodium concentration increases IFT observed between crude oil and Low Sal solutions. 


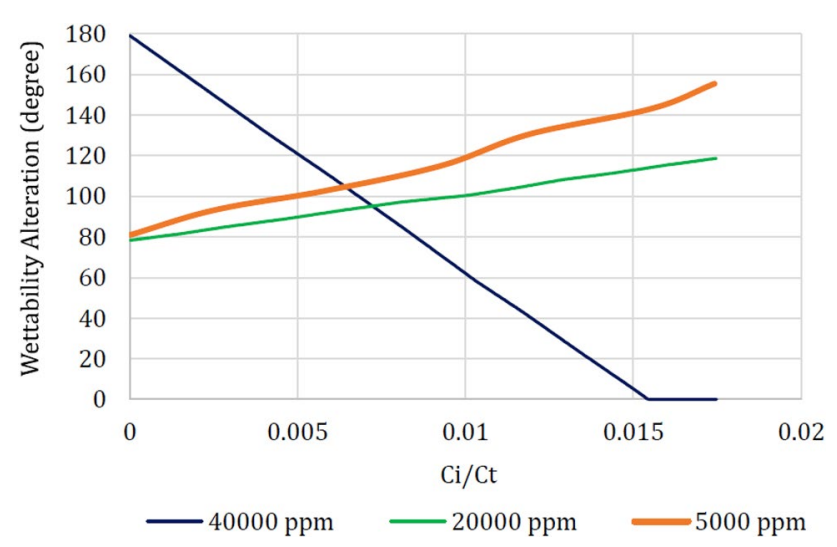

Fig. 10 Effect of calcium ion on wettability alteration

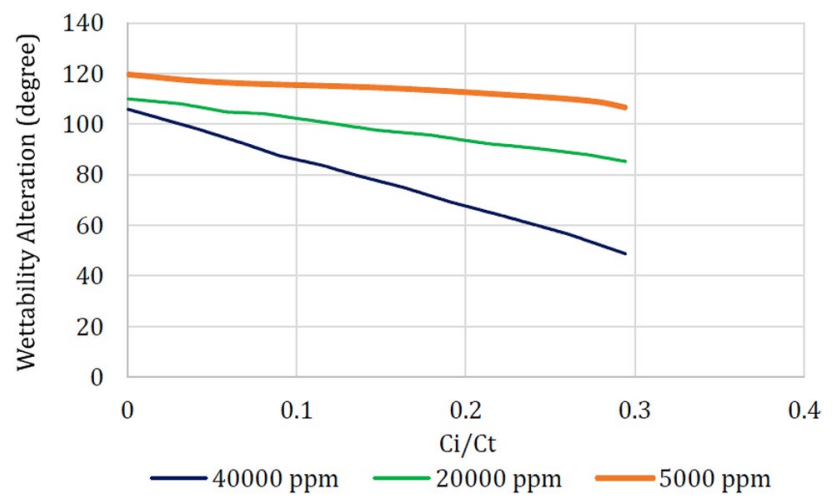

Fig. 11 Effect of sodium ion on wettability alteration

\section{Wettability alteration tests}

Like the process performed on IFT results, the observed wettability alterations are analyzed using Design-Expert software. The observed alterations are presented in Fig. 7.

Analysis of each TDS group results in four different plots that show the approximate effects of one controlling ion (i.e., sulfate, magnesium, calcium, and sodium) at other ions' average concentrations. In Figs. 8, 9, 10 and 11, ions' effect on observed wettability alteration is presented.
Figure 8 shows that except in 40,000 ppm, increasing sulfate ion concentration reduced observed contact angle alteration. But it must be mentioned that despite its negative slope at 20,000 and 5,000 ppm solutions, sulfate ion shows a positive contact angle alteration, which means its positive effect. Increasing sulfate ion concentration lowers its positive impact on the alteration process. Magnesium (the result is presented in Fig. 9) is somehow the only ion that shows positive results and slope (i.e., increasing $\mathrm{Mg}$ concentration always increases alteration). From curves provided for this ion, lowering solutions TDS does not change ions affect a lot. Calcium shows a trend completely different from other ions. Figure 10 shows that at higher salinity, $\mathrm{Ca}^{+}$completely shows a sharp negative slope. But at 20,000 and 5,000 ppm TDS values, increasing $\mathrm{Ca}^{+}$concentration increases contact angle alterations.

\section{Free imbibition tests}

From all observed results (wettability alterations and IFT tests), six different conditions (two from each TDS) are elected to be studied in free imbibition tests. In Table 3, these conditions are presented.

In addition to the selected Low Sal solutions, a test is performed with reservoir brine for comparison. Recorded oil recovery factor versus time for different samples is presented in Fig. 12.

Although it is not an appropriate comparison, by checking the results obtained from each TDS pairs, it is possible to say that by increasing $\mathrm{Ca}^{+}$and $\mathrm{Na}^{+}$concentration and decreasing $\mathrm{Mg}^{2+}$ concentrations, ultimate recovery and imbibition rates are reduced.

\section{Core floods recovery and relative permeability measurements}

The final part of the experimental section of this study aimed to obtain relative permeability alterations in addition to the recovery factor during smart water injection for field-scale simulations. As mentioned before in this study, two solutions are selected for unsteady-state relative permeability
Table 3 Selected conditions for free imbibition test

\begin{tabular}{|c|c|c|c|c|c|c|}
\hline \multirow[t]{2}{*}{ Test-ID } & \multicolumn{5}{|c|}{ Ions concentration (ppm) } & \multirow{2}{*}{$\begin{array}{l}\text { Wettability } \\
\text { alteration } \\
\text { (deg.) }\end{array}$} \\
\hline & Core number & $\mathrm{SO}_{4}^{2+}(\mathrm{ppm})$ & $\mathrm{Mg}^{2+}(\mathrm{ppm})$ & $\mathrm{Ca}^{+}(\mathrm{ppm})$ & $\mathrm{Na}^{+}(\mathrm{ppm})$ & \\
\hline $40,000-1$ & C6 & 7439.95 & 7269.86 & 154.00 & 5535.08 & 126.8 \\
\hline $40,000-9$ & $\mathrm{C} 3$ & 0.00 & 9716.00 & 700.00 & 5036.13 & 113.1 \\
\hline $20,000-22$ & $\mathrm{C} 2$ & 6922.63 & 2367.50 & 176.73 & 5900.92 & 100.7 \\
\hline $20,000-23$ & $\mathrm{C} 4$ & 0.00 & 5105.50 & 0.00 & 2518.06 & 118.1 \\
\hline $5000-34$ & $\mathrm{C} 1$ & 1730.65 & 591.87 & 44.18 & 1475.23 & 115.5 \\
\hline $5000-35$ & $\mathrm{C} 5$ & 0.00 & 1276.38 & 0.00 & 629.52 & 125.1 \\
\hline
\end{tabular}




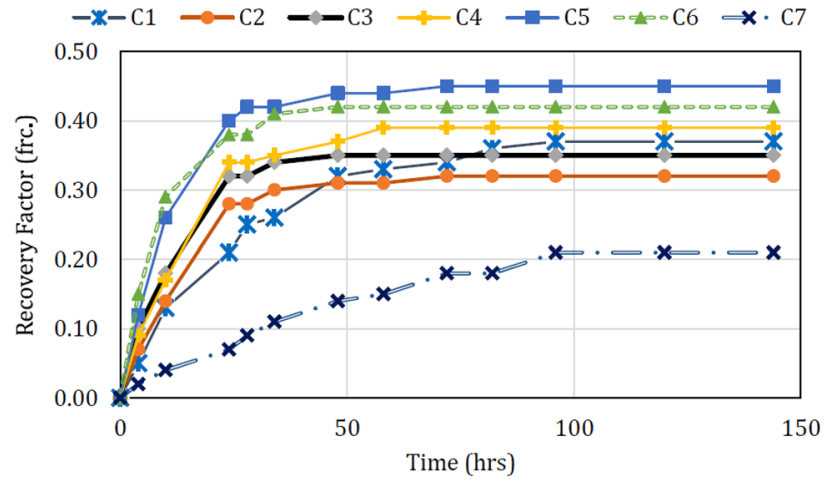

Fig. 12 Oil recovery factor during free imbibition tests

measurements from all conditions. In Table 4, these two conditions are presented.

Recovery factors observed during core flooding sequences are presented in Figs. 13 and 14 for $\mathrm{CF} 1$ and CF2, respectively.

For unsteady-state relative permeability measurements, the experiment section's procedure sequences are applied to both core plugs. Cydarex software is used for relative permeability estimations (using the JBN method and LET $3^{\text {rd }}$ order correlation). Figures 15 and 16 alter relative permeability curves (versus normalized saturation) presented for CF-1 and CF-2.

In Table 5, endpoints of both cores (before and after smart water flooding) are provided.

Because unsteady-state relative permeability measurements are conducted at high injection rates (i.e., to satisfy $\mathrm{LQ} \mu>>1$ condition), capillary pressure is nearly ignored. But it is also possible to estimate capillary pressure if history matching is used as the estimation tool. In Figs. 17 and 18 , capillary pressure is estimated before and after Low Sal flood for both cases (i.e., CF1 and CF2) are presented.

\section{Simulation}

\section{PVT analysis and EOS tuning}

PVTi module of the Schlumberger package is used to analyze the PVT-lab report of the field crude oil provided by
NISOC RIPI. Fluid composition and overall properties of reservoir crude are presented in Table 6.

Nearly all performed tests are imported into the software (after appropriate quality control). PR-3 EOS using the density correction parameter (Peneloux) is used and tuned to predict reservoir fluid behaviors. Figures 19, 20, 21, and 22 shows some of the EOS tuning results.

\section{Test simulations}

Based on the laboratory's observed data, a one-dimensional model is prepared to use a history matching technique to estimate both relative permeability and capillary pressure of used core plugs in the laboratory. LET 3rd-order and logarithmic correlations are chosen as the relative permeability and capillary pressure correlations. Endpoint saturations are obtained by applying material balance equations on the observed production data, while endpoint effective permeabilities are calculated using Darcy's equation before and after water injection. Optimizations are applied to minimize the difference between experimental and simulated DP, water production, and oil production. The following figures show the difference between observed and simulated pressure difference for both core plugs (i.e., CF1 and CF2) during both water flooding and Low Sal flooding (Figs. 23, 24, 25 , and 26)

By applying the history matching procedure, correlations parameters are estimated to calculate relative permeability and capillary pressure presented before and to estimate their alterations after applying Low Sal solutions. After relative permeability and capillary pressure estimations, Low Sal sequences are simulated using Schlumberger Eclipse (E100) by applying the Low Sal model. A brief instruction for preparing data files for eclipse Low Sal is provided in "Appendix". In Fig. 27, cumulative oil production obtained by E100 simulation is provided.

The main problem with results obtained using the Eclipse Low Sal model is the time lag between the initiation of Low Sal injection and tertiary oil production. Equilibration assumptions behind the wettability alteration algorithm in this simulator result in faster tertiary recovery. In reality, the alteration itself takes time (from the graph presented above, it nearly needs $1-2 \mathrm{~h}$ ). Altering model parameters
Table 4 Selected conditions for relative permeability measurements

\begin{tabular}{llllllll}
\hline Test-ID & \multicolumn{2}{l}{ Ions concentration $(\mathrm{ppm})$} & & $\begin{array}{l}\text { Amott } \\
\text { recovery } \\
\text { (frc.) }\end{array}$ \\
\cline { 2 - 6 } & Corename & $\mathrm{SO}_{4}{ }^{2+}(\mathrm{ppm})$ & $\mathrm{Mg}^{2+}(\mathrm{ppm})$ & $\mathrm{Ca}^{+}(\mathrm{ppm})$ & $\mathrm{Na}^{+}(\mathrm{ppm})$ & $\begin{array}{l}\text { Wettability } \\
\text { alteration } \\
\text { (deg.) }\end{array}$ & \\
\hline $5000-35$ & $\mathrm{CF}-1$ & 0 & 1276.4 & 0 & 629.5 & 125.1 & 0.45 \\
$40,000-1$ & $\mathrm{CF}-2$ & 7439.9 & 7269.9 & 154 & 5535.1 & 126.8 & 0.42 \\
\hline
\end{tabular}




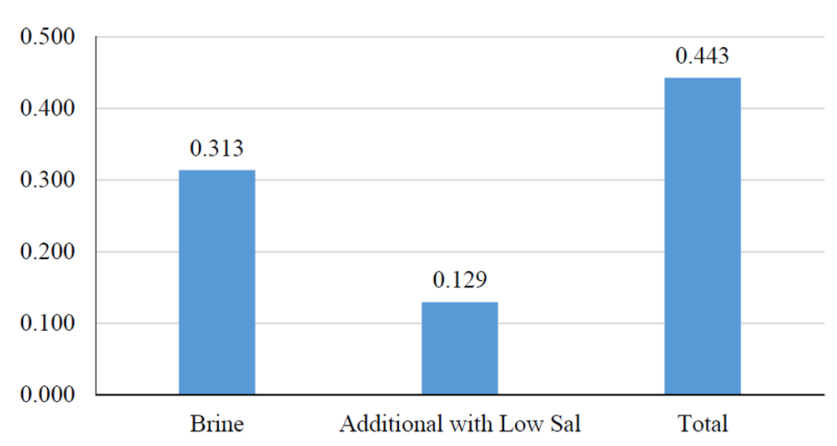

Fig. 13 Recoveries observed in $\mathrm{CF} 1$

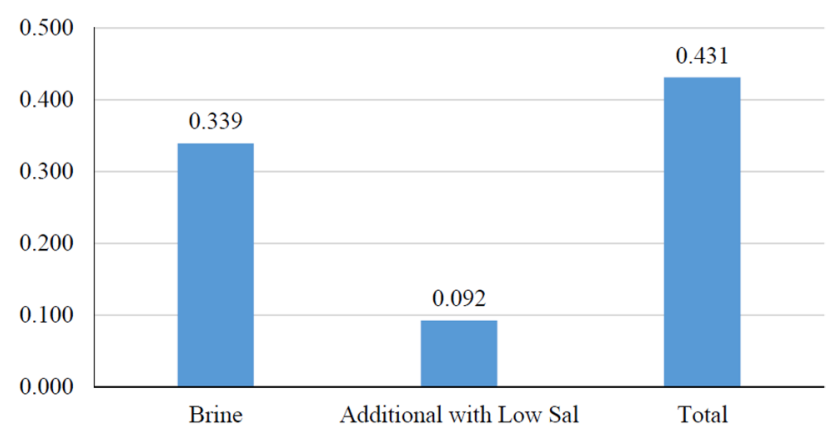

Fig. 14 Recoveries observed in CF2

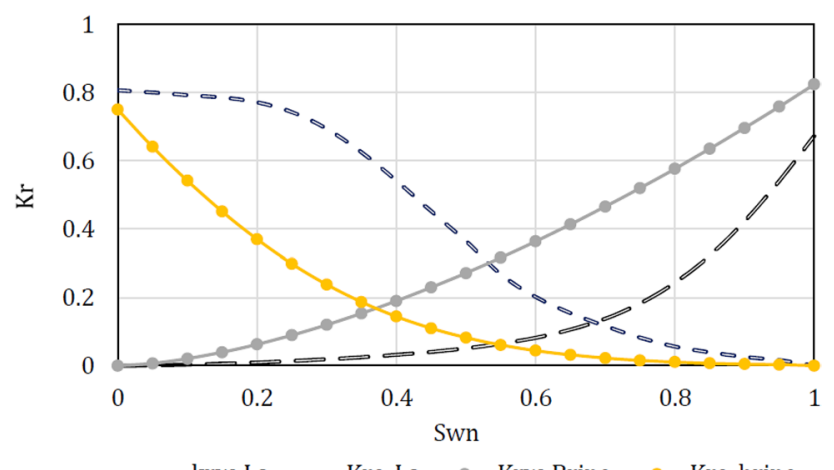

Fig. 15 Normalized relative permeability's of core CF1, before and after Low Sal floods

such as relative permeability does not result in a better match between simulation and observations.

\section{Sector model}

A synthetic sector model $(4 \mathrm{~km} * 4 \mathrm{~km})$ is prepared from data sets available from all prepared core plugs using Schlumberger Petrel (ver. 2010). A stochastic property distribution based on the normal Gaussian method is introduced to the model. The model's size makes it possible to place five producers and four injectors in the model based on the average

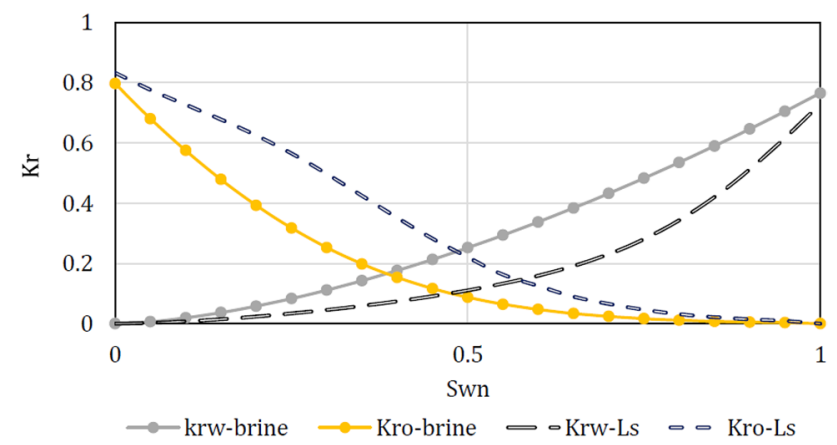

Fig. 16 Normalized relative permeability's of core CF2, before and after Low Sal floods

Table 5 Saturation endpoints observed during relative permeability tests

\begin{tabular}{llll}
\hline Core & Flooding sequence & $\mathrm{S}_{\mathrm{wc}}$ & $\mathrm{S}_{\text {or }}$ \\
\hline $\mathrm{CF} 1$ & Brine & 0.33 & 0.46 \\
& Smart water & 0.39 & 0.34 \\
$\mathrm{CF} 2$ & Brine & 0.38 & 0.41 \\
& Smart water & 0.42 & 0.33 \\
\hline
\end{tabular}

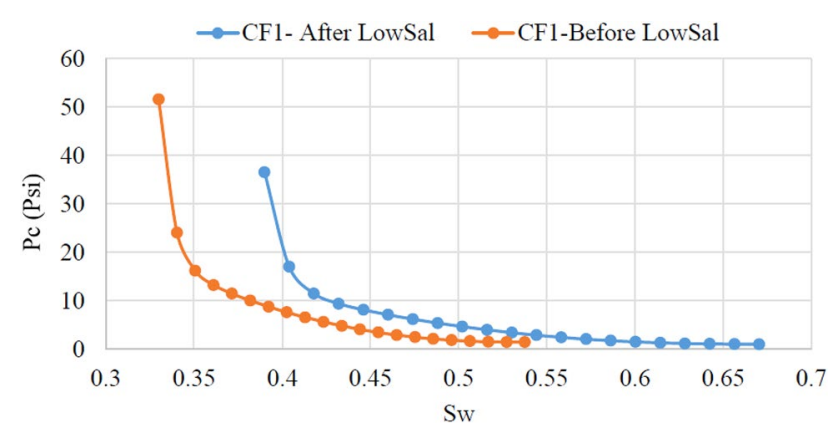

Fig. 17 Pc of CF1 before and after Low Sal

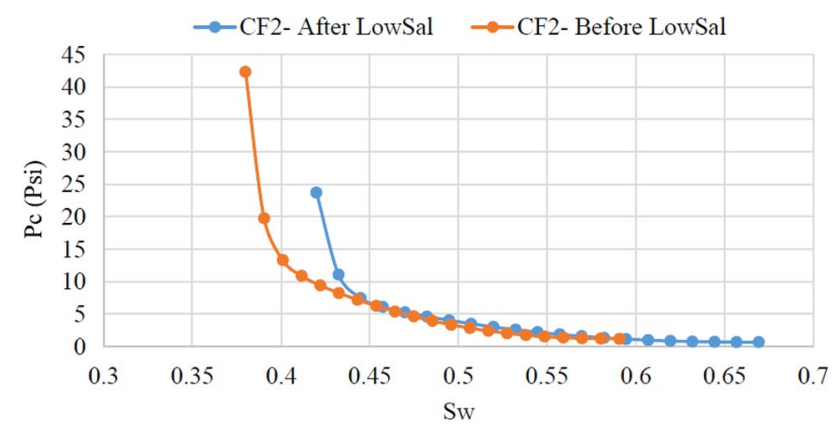

Fig. 18 Pc of CF2 Before and after Low Sal 
Table 6 PVT properties of crude oil

\begin{tabular}{llll}
\hline Components & Residual oil & Associated gas & Reservoir oil \\
\hline $\mathrm{H} 2 \mathrm{~S}$ & 0 & 0 & 0 \\
$\mathrm{~N} 2$ & 0 & 0.22 & 0.13 \\
$\mathrm{CO} 2$ & 0 & 0.35 & 0.2 \\
$\mathrm{C} 1$ & 0 & 68.03 & 40.26 \\
$\mathrm{C} 2$ & 0.08 & 12.43 & 7.39 \\
$\mathrm{C} 3$ & 0.59 & 8.13 & 5.05 \\
iC4 & 0.94 & 1.54 & 1.3 \\
nC4 & 1.67 & 3.94 & 3.02 \\
iC5 & 0.2 & 1.31 & 0.86 \\
nC5 & 0.07 & 1.51 & 0.92 \\
C6 & 7.51 & 1.47 & 3.93 \\
C7 & 6.73 & 0.8 & 3.22 \\
C8 & 6.61 & 0.27 & 2.86 \\
C9 & 8.42 & 0.01 & 3.44 \\
C10 & 6.33 & 0 & 2.58 \\
C11 & 5.73 & 0 & 2.34 \\
C12+ & 55.12 & 0 & 22.5 \\
The molecular weight of residual oil & & & 236 \\
The molecular weight of the C12 fraction & & & 340 \\
The molecular weight of reservoir oil & & & 112 \\
Sp.Gr. of C12 Fraction @ 60/60 F & & & 0.9274 \\
GOR & & & 680.31 scf/STB \\
Bubble point pressure & & &
\end{tabular}

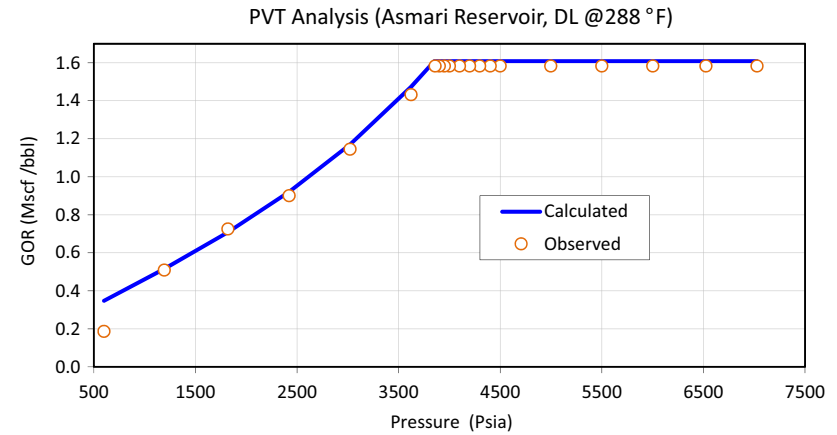

Fig. 19 GOR value of Tuned EOS

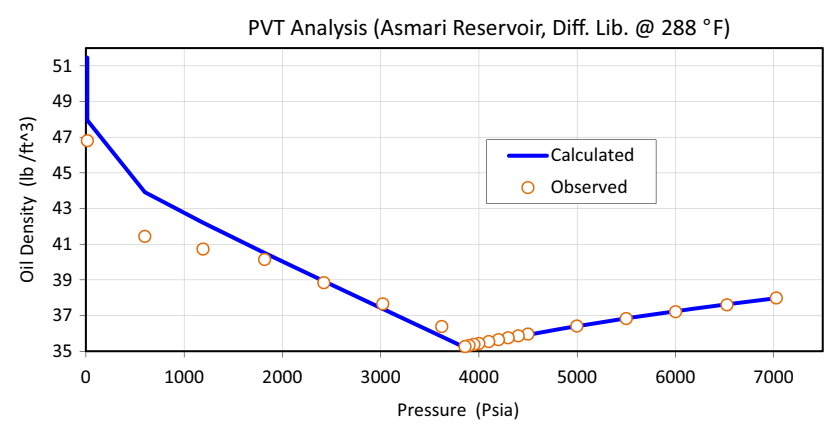

Fig. 20 Oil density calculated by tuned EOS

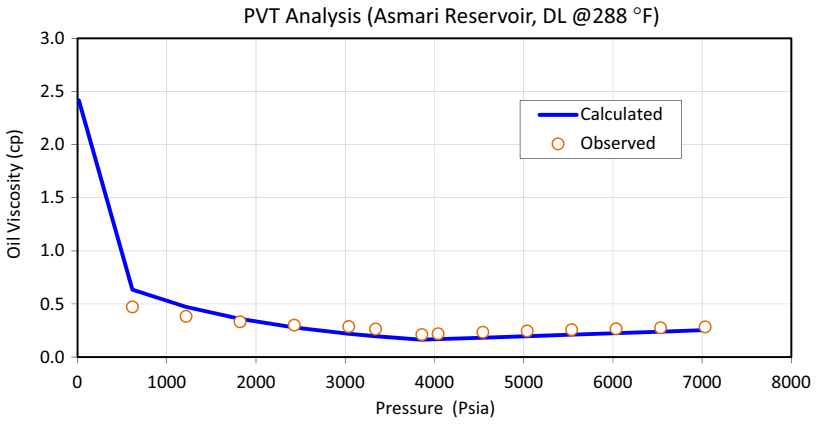

Fig. 21 Liquid viscosity from EOS

well spacing distance used in the reservoir region (nearly $2 \mathrm{~km}$ ). The main goal of this simulation is to estimate Low Sal process efficiency under typical field constraints. Well locations are presented in Fig. 28. The prepared model's porosity and permeability distribution is shown in Figs. 29, 30 , respectively. It may be useful to mention that moving average methodology predicts property distribution concerning the prepared model's location.

Relative permeability alteration results obtained from both core flooding tests are imported into Eclipse software to check each test's efficiency in the reservoir sector. The constraints presented in Table 7 are applied to the model. 


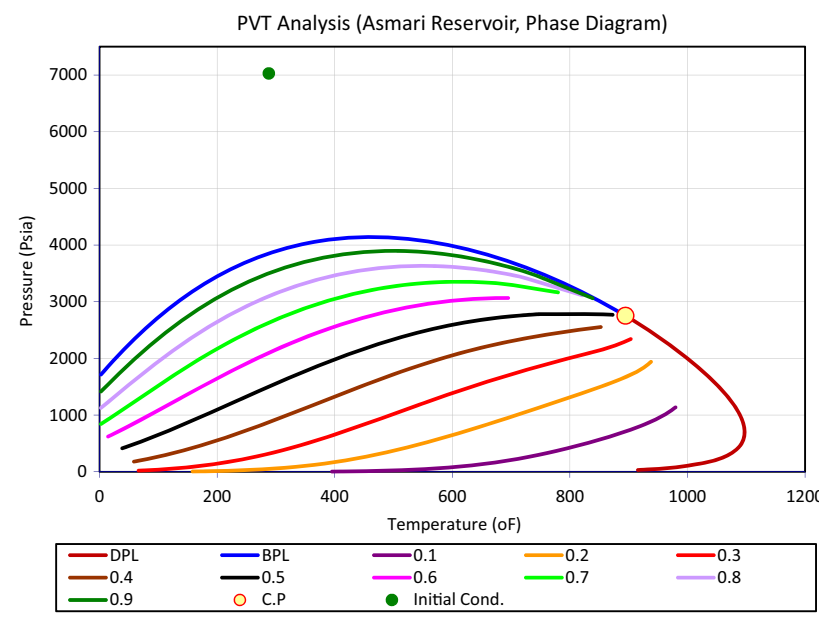

Fig. 22 Phase envelope after EOS tuning

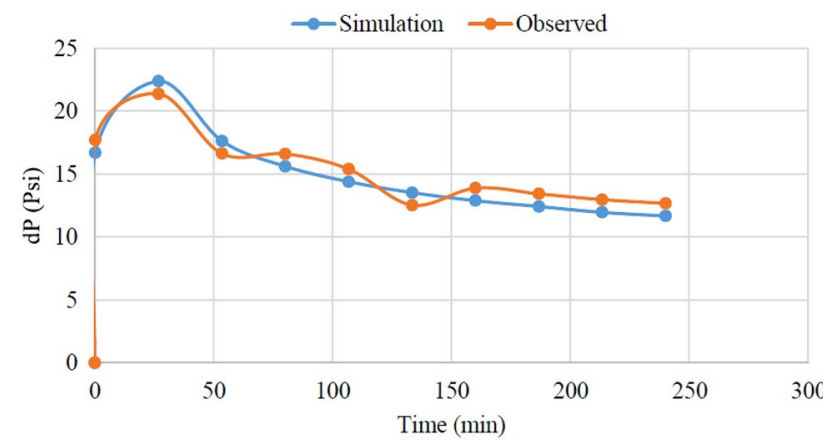

Fig. 23 DP during CF1 water flood

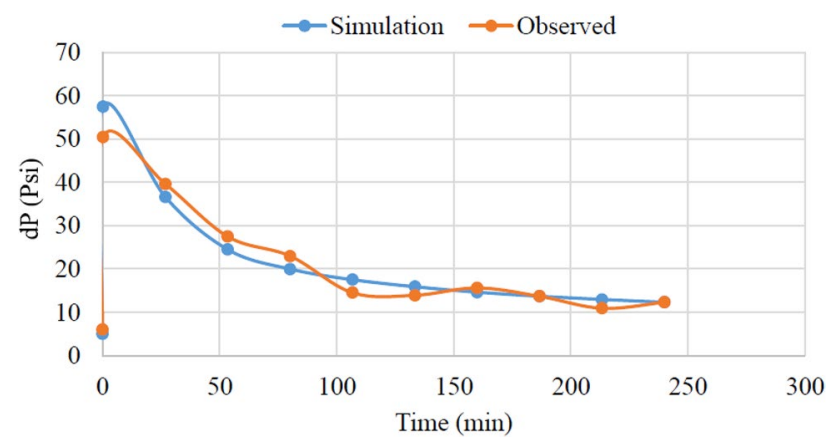

Fig. 24 DP during CF1 Low Sal flood

To find the best time to initiate tertiary recovery, Low Sal solutions are injected at different production water cuts (i.e., from the beginning, at water breakthrough, at 10, 20, 30 , and $40 \%$ water cuts).

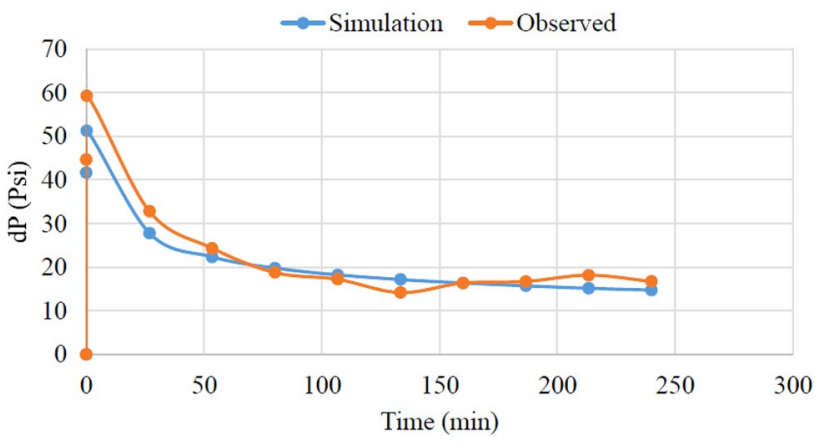

Fig. 25 DP during CF2 water flood

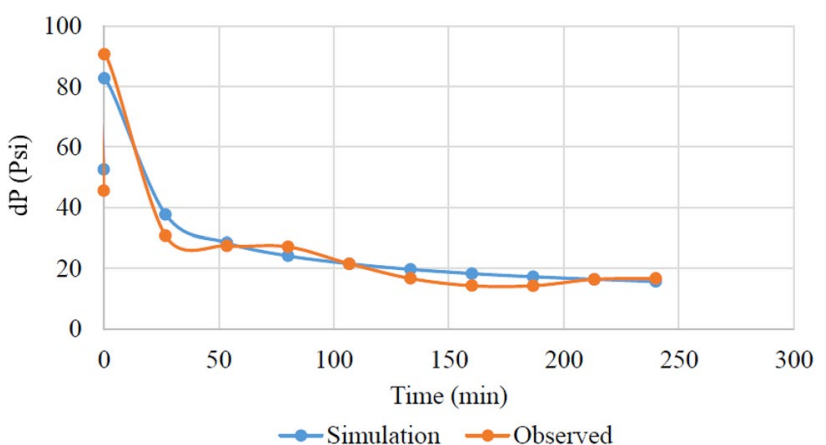

Fig. 26 DP during CF2 Low Sal flood

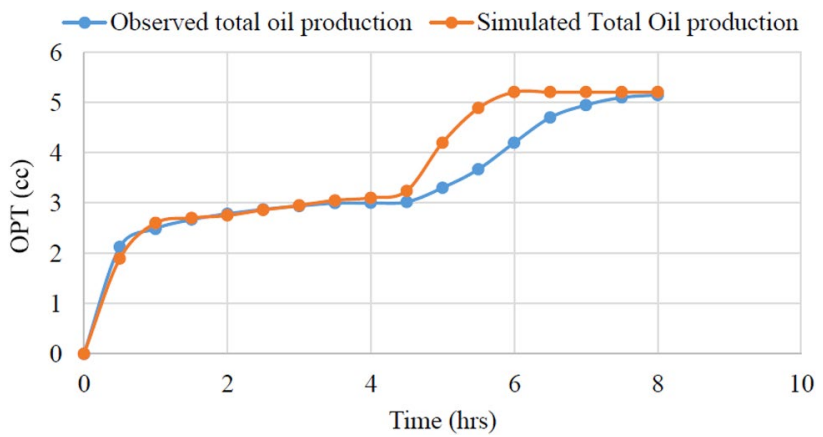

Fig. 27 Differences between simulated and observed OPT

\section{Low Sal solution 1 (CF1 data)}

In the first set of simulations, results obtained from core flood tests named CF1 are used. Figures 31, 32, 33 field oil recovery, oil production rate, and production water cuts of all scenarios are plotted. The best condition is to inject Low Sal solution from the beginning (i.e., secondary recovery). But for the simulated conditions, it is also possible to start tertiary recovery after observing a $20 \%$ water cut in field production. 


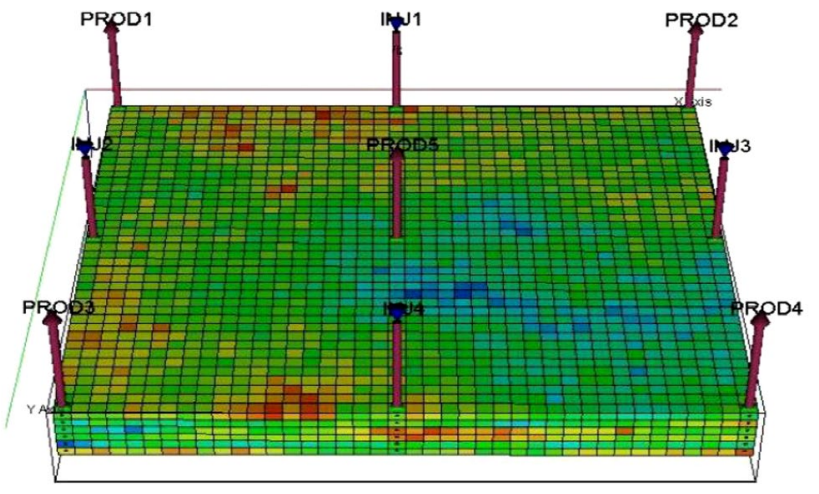

Fig. 28 Well locations proposed to the model

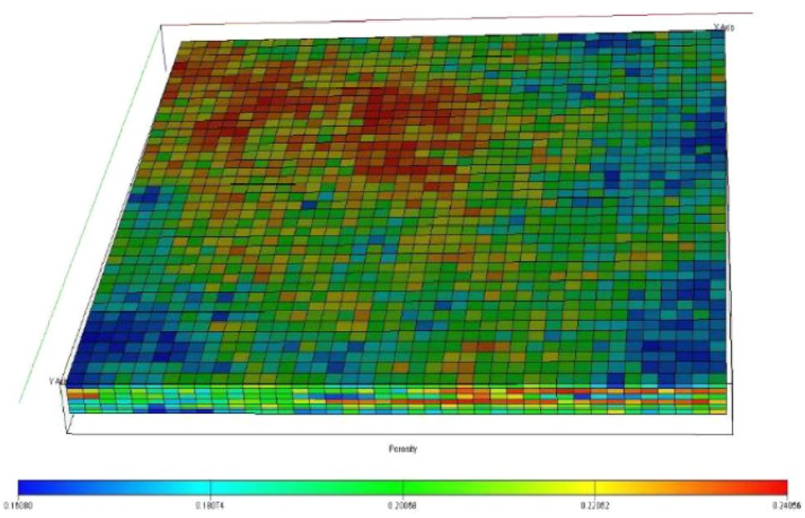

Fig. 29 Porosity distribution in the prepared sector model

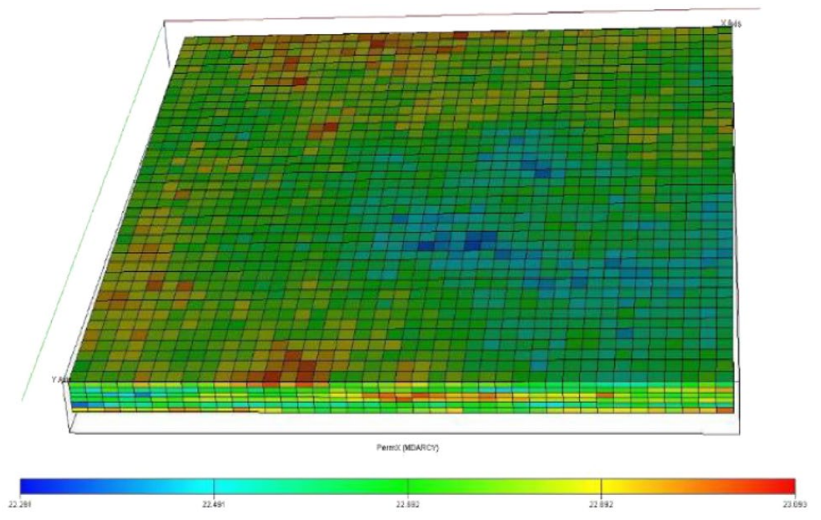

Fig. 30 Permeability distribution in the proposed sector model

Based on the reservoir properties and applied water-cut constraint, the last chance to achieve an appropriate recovery factor using smart water (the solution used for CF-1) is when the production water cut reaches $20 \%$. Postponing tertiary recovery further lowers ultimate recovery because the high volume of injected non-modified water causes water-cut limits to be violated. This violation encloses producers and ceases oil production.
Table 7 Restrictions applied in sector simulation

\begin{tabular}{lll}
\hline Constraint & Unit & Value \\
\hline Oil production rate & STB/Day & 2,000 \\
Producer BHP & psia & 3,000 \\
Maximum well water cut & Fraction & 0.8 \\
Well water injection rate & STB/Day & 20,000 \\
Injection BHP & psia & 10,000 \\
\hline
\end{tabular}

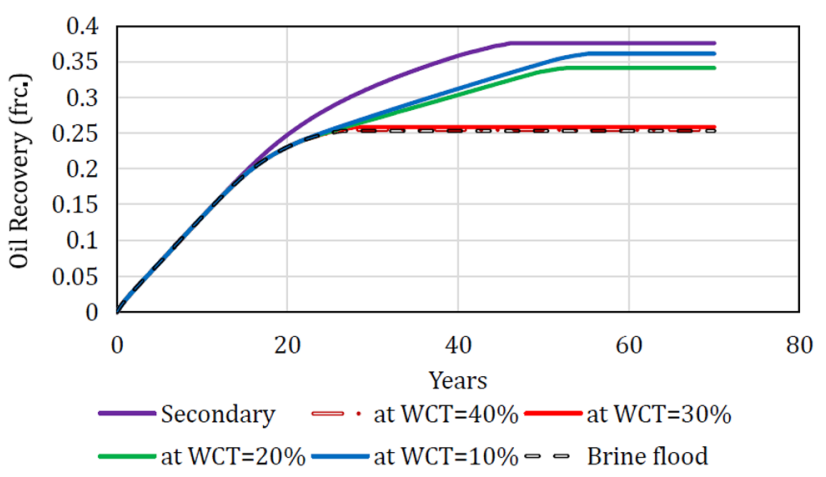

Fig. 31 Simulated oil recovery for different Low Sal injection initiation times using CF1 relative permeability's

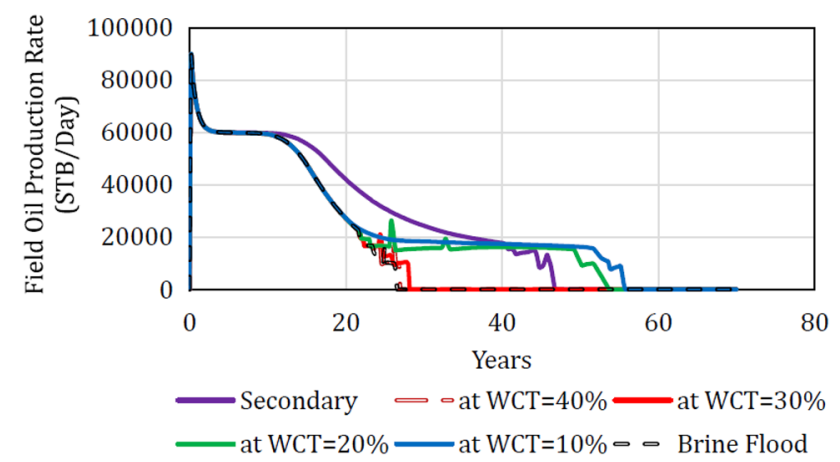

Fig. 32 The simulated oil production rate for different Low Sal injection initiation time using relative permeability's

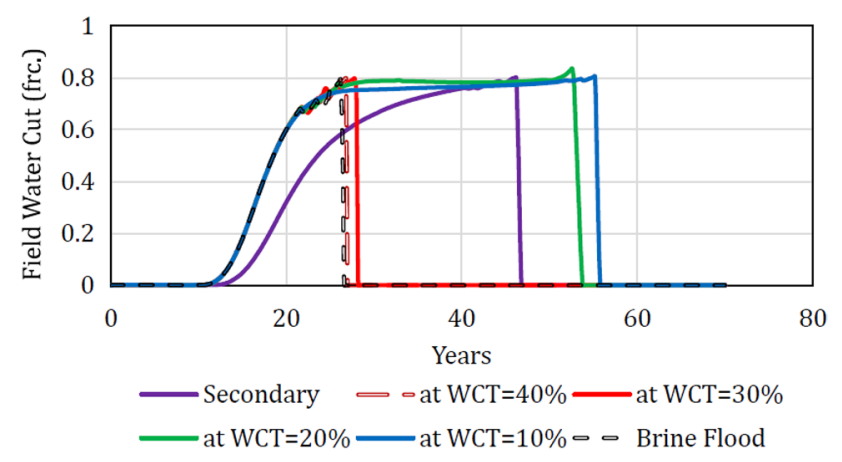

Fig. 33 Simulated production water cut for different Low Sal injection initiation time using CF1 relative permeability's 


\section{Low Sal solution 2 (CF2 data)}

In the second set of simulations, results obtained from core flood tests named CF2 are used. Figures 34, 35, and 36 show that field oil recovery, oil production rate, and production water cuts of all scenarios are plotted. To use the benefits of Low Sal solution in this condition and applied constraints, the only way is to apply the smart water injection during the second production stage.

The only way to achieve additional recovery using this solution (i.e., the solution used for CF-2) is to start tertiary recovery (i.e., Low Sal injection) right after primary production. This is because lower wettability alteration of this solution lowers microscopic sweep efficiency, resulting in a thinner oil bank. Thin-oil banks will be produced fast, and the water-cut limit will be violated. This violation will cease economic production from producer wells.

\section{Conclusions}

This study tried to prepare a foundation for future research on the smart water injection process. Different tests (i.e., wettability, IFT, free imbibition, and core flooding) are performed to estimate the effect of Low Sal water injection on oil recovery. During IFT and wettability tests, it is tried to evaluate every ion's impact utilizing statistically based approaches (i.e., RSM method). From all performed experiments and simulations in this study, it is possible to conclude that:

\section{IFT tests}

- The studied reservoir contained high salinity brine, which may increase the chance of observing significant Low Sal effects.

- As the results show, no significant IFT reduction was observed using Low Sal solutions; maximum IFT reduction is in the range of 3-4 dyne $/ \mathrm{cm}$.

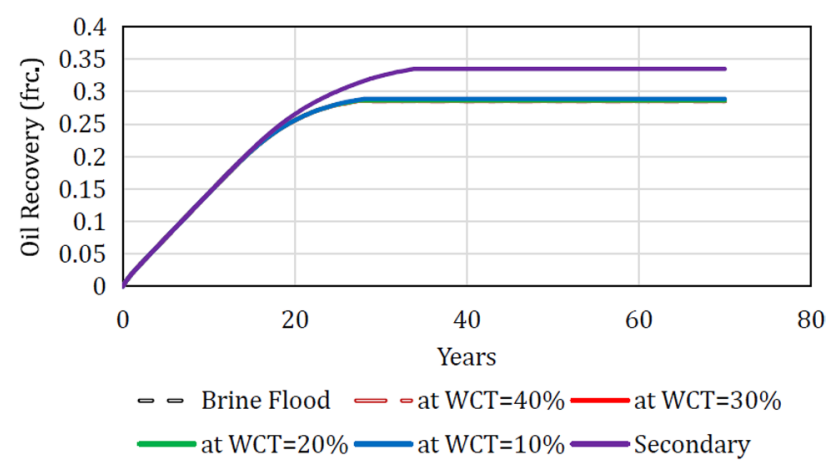

Fig. 34 Simulated oil recovery for different Low Sal injection initiation times using CF2 relative permeability's

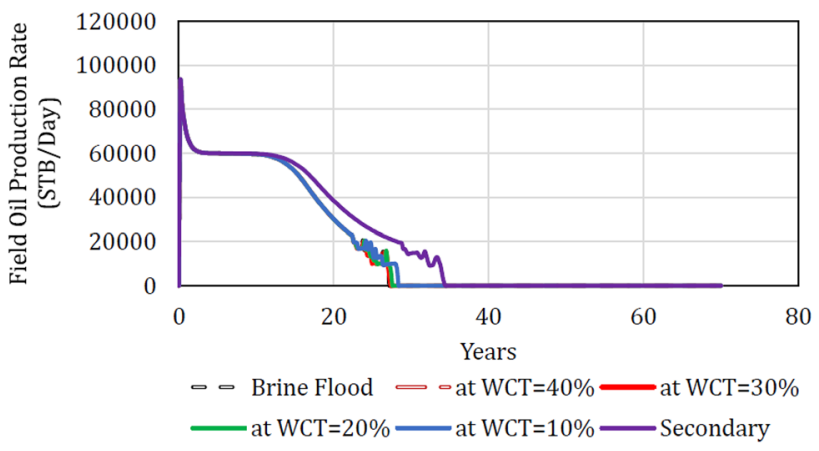

Fig. 35 The simulated oil production rate for different Low Sal injection initiation times using $\mathrm{CF} 2$ relative permeability's

- Based on the results provided for sulfate ion, at Low Sal (i.e., $5000 \mathrm{ppm}$ ), increasing sulfate concentration lowers IFT, while in higher salinities, increasing sulfate ion increases IFT.

- All ions seem to be more effective at lower salinities except sodium. Increasing sodium concentration may increase IFT, especially at lower TDS values.

- In all salinities, increasing magnesium concentration decreases IFT.

\section{Wettability tests}

- Rock samples were nearly pure calcite (more than $95 \%$ calcite), showing significant alteration by aging in Low Sal solutions. This may provide the idea that wettability alteration may be active in calcites (whatever anhydrite or dolomite exists or not).

- Lowering solutions TDS does not always mean increasing Low Sal efficiency.

- Based on the results provided for sulfate ion, at high salinities (i.e., 40,000 ppm) existence of sulfate concentration shows a positive effect on alteration. In contrast,

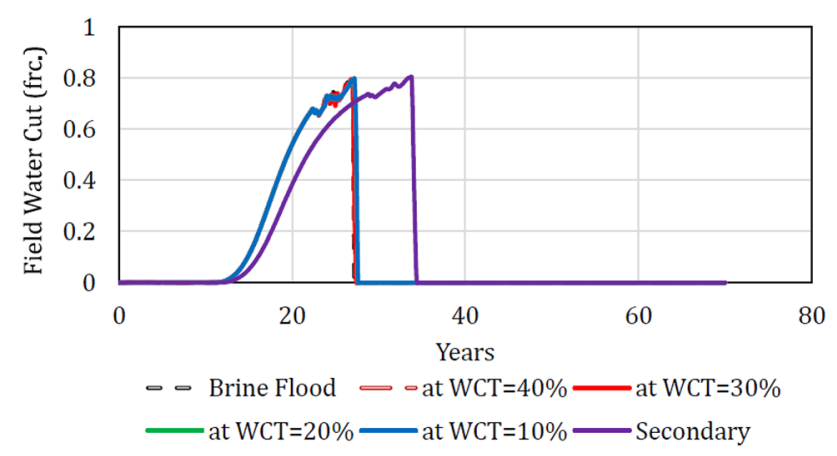

Fig. 36 Simulated production water cut for different Low Sal injection initiation times using $\mathrm{CF} 2$ relative permeability's

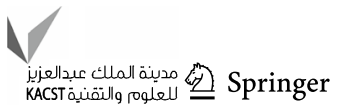


in lower TDS values, increasing sulfate concentration decreases the observed alteration.

- Increasing sodium concentration lowers the chance of appropriate alteration.

- Lowering solutions TDS helps to decrease sodium's negative effect.

- In all salinities, increasing magnesium concentration helps in the alteration process.

- Increasing calcium concentration at high TDS (i.e., $40,000 \mathrm{ppm}$ ) decreases the amount of wettability alteration. In comparison, in lower TDS values $(20,000$ and $5000 \mathrm{ppm}$ ), calcium shows a positive effect, and its concentration enhances the alteration process.

\section{Free imbibition, core flood and simulation}

- Observed data from Amott tests using 40,000 ppm solutions shows that sulfate ion's existence increases free imbibition recovery.

- In free imbibition tests using 20,000 ppm and $5000 \mathrm{ppm}$ solutions, increasing sulfate and decreasing magnesium concentrations lowers both imbibition and ultimate oil recovery rates.

- Decreasing salinity from reservoir brine to lower values (in all conditions) increases imbibition rate and ultimate oil recovery.

- The best two conditions observed from all performed tests are used to evaluate relative permeability changes during Low Sal flooding. It may be concluded that both lowering TDS and sodium concentration and increasing magnesium concentration helps in the alteration process.

- A sector model simulation is performed to evaluate flooding efficiency in the selected field. By using relative permeability changes observed in the CF1 test, additional recovery is observed up to 12 percent, while using CF2 data, the maximum obtained recovery (in addition to water flood) is nearly $7 \%$.

- For each solution, a set of simulations are performed to check the efficiency of tertiary floods under applied constraints, especially water-cut limitation. During simulations based on CF1, using Low Sal solutions at water cut equals or below $10 \%$ lowers recovery rate while lowers ultimate recovery less than $5 \%$.

- This indicates that an economic study is necessary to evaluate the best scenario. Applying tertiary floods after reaching $30 \%$ of water cut does not alter ultimate oil recovery under the current water-cut constraints.

- Applying smart water in the second phase (i.e., instead of normal water flood) increases both ultimate recovery and the candidate reservoir's oil production rate.

- Simulations based on CF2 relative permeability data sets show that the only way to increase the recovery factor under the current water-cut limitation is to apply smart water directly after primary production (i.e., instead of normal water flood).

Acknowledgements The authors would like to thank Sarvak Azar Engineering and Development Company (SAED), Oil Industries Engineering and Construction Group (OIEC), for providing crude oil, and Dr. Ali Akbar Eftekhari from the Danish Hydrocarbon Research and Technology Centre (DHRTC), Technical University of Denmark (DTU), for his assistance and advice in matters concerning the experimental setup and procedure.

Funding The author(s) received no specific funding for this work.

Open Access This article is licensed under a Creative Commons Attribution 4.0 International License, which permits use, sharing, adaptation, distribution and reproduction in any medium or format, as long as you give appropriate credit to the original author(s) and the source, provide a link to the Creative Commons licence, and indicate if changes were made. The images or other third party material in this article are included in the article's Creative Commons licence, unless indicated otherwise in a credit line to the material. If material is not included in the article's Creative Commons licence and your intended use is not permitted by statutory regulation or exceeds the permitted use, you will need to obtain permission directly from the copyright holder. To view a copy of this licence, visit http://creativecommons.org/licenses/by/4.0/.

\section{Appendix: Eclipse Low Sal model}

Simulation of Low Sal using Schlumberger eclipse:

To prepare a simulation model (data file) for this process, the following steps may be followed:

1. A basic mode must be prepared for Eclipse black oil (E100).

2. In the RUNSPEC section, introduce a low-salinity model by entering the LOW SALT keyword.

3. In PROPS section:

a. Enter two sets of saturation functions using keywords such as SWOF and SWFN.

b. Enter the LSALTFNC keyword. This keyword is used to dedicate each set of saturation functions to one condition (i.e., one to High Sal condition and one to Low Sal).

c. Enter PVTWSALT instead of PVTW to introduce brine's thermodynamic behavior as a function of salts concentrations.

4. In the REGIONS section, enter the keyword LWSLTNUM to specify the blocks (i.e., simulation grids) which may be affected by the LOW Sal flood.

5. If an aquifer is presented in the model, enter the salinity of water, which may flow into the aquifer's reservoir.

6. In the SOLUTION section, initial reservoirs brine salinity must be introduced with the SALTVD keyword.

7. In the SCHEDULE section, water injectors' water salinity must be introduced to the model using the WSALT keyword. 
Eclipse assumes a linear interpolation between entered saturation functions, which is weighted by blocks salt concentrations.
In the following, an example of a data file prepared for low-salinity simulation is provided.

\section{RUNSPEC}

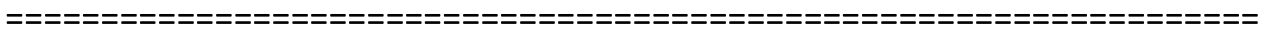

TITLE

Freshwater injection /

DIMENS

$15153 /$

OIL

WATER

GAS

LOW SALT

METRIC

TABDIMS

212020120 /

WELLDIMS

$31013 /$

START

1 'JAN' 1990 /

UNIFIN

UNIFOUT

ACTDIMS

10 /

UDQDIMS

--MAX NO. MAX NO. MAXNO. MAXNO. MAX MAX MAX MAX MAX

MAX

--FUNCTIONS ARGUMNTS CONECTION FIELD GRUP REGN SEGMNT

WELL AQUIFER BLOCK

$\begin{array}{llllllllllll}12 & 12 & 2 & 10 & 0 & 0 & 4 & 0 & 10 & 0 & 4\end{array}$ 


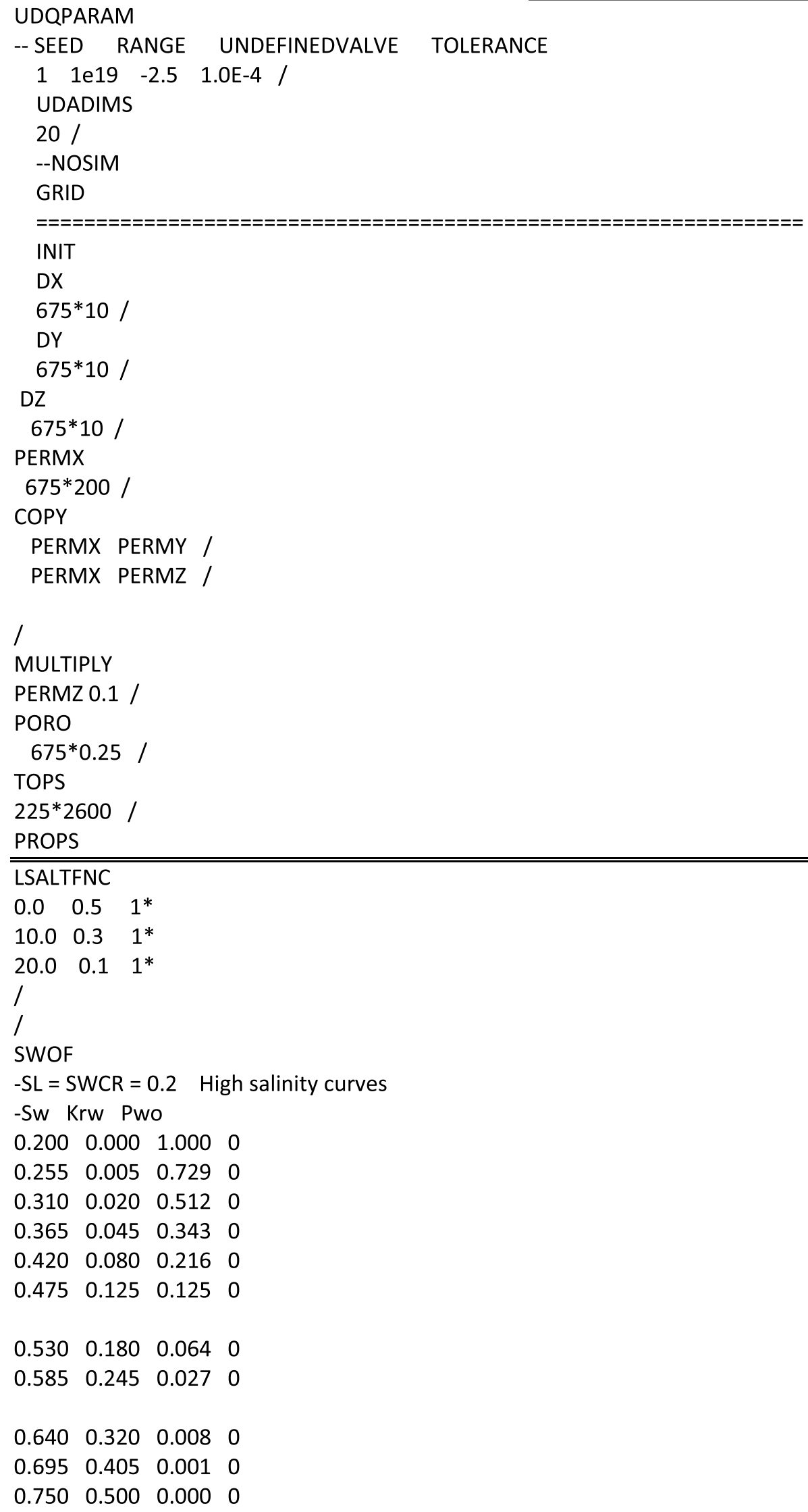




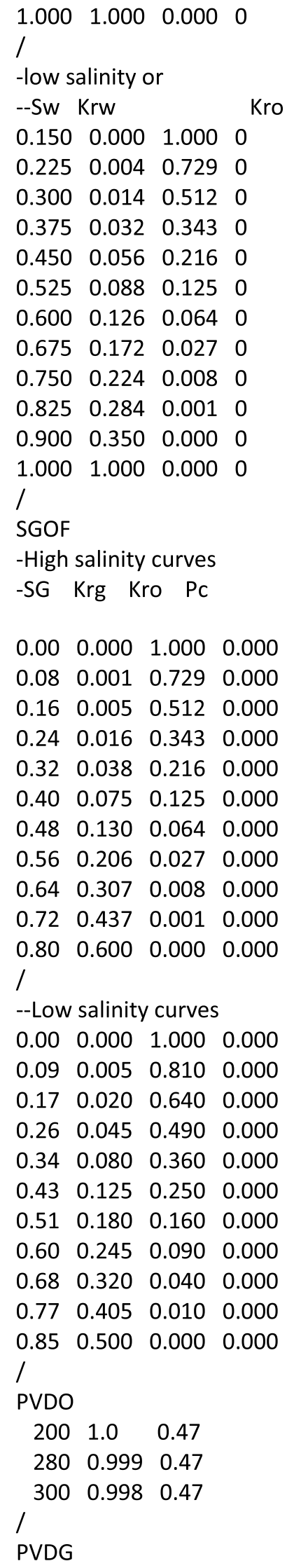




$\begin{array}{lll}\text { - PGAS BGAS } & \text { VISGAS } & \\ 10.00000 & 0.12668 & 0.01316 \\ 35.78947 & 0.03436 & 0.01361 \\ 61.57895 & 0.01944 & 0.01426 \\ 87.36842 & 0.01340 & 0.01506 \\ 113.15789 & 0.01017 & 0.01601 \\ 138.94737 & 0.00820 & 0.01711 \\ 164.73684 & 0.00689 & 0.01832 \\ 190.52632 & 0.00599 & 0.01962 \\ 216.31579 & 0.00533 & 0.02097 \\ 242.10526 & 0.00484 & 0.02234 \\ 270.00000 & 0.00444 & 0.02383 \\ 293.68421 & 0.00417 & 0.02507 \\ 319.47368 & 0.00393 & 0.02640 \\ 345.26316 & 0.00374 & 0.02770 \\ 371.05263 & 0.00358 & 0.02896 \\ 396.84211 & 0.00344 & 0.03019 \\ 422.63158 & 0.00332 & 0.03138 \\ 448.42105 & 0.00322 & 0.03254 \\ 474.21053 & 0.00313 & 0.03367 \\ 500.00000 & 0.00305 & 0.03476 \\ \text { / } & & \\ \text { ROCK } & & \end{array}$

270.3E-5 /

DENSITY

--O W $\mathrm{g}$

850. 1000. $1.2 /$

PVTWSALT

$270.0 \quad 0.0 /$

$\begin{array}{lllll}0.0 & 1.030 & 4.6 \mathrm{E}-5 & 0.5 & 0.0\end{array}$

$\begin{array}{lllll}10.0 & 1.030 & 4.6 \mathrm{E}-5 & 0.5 & 0.0 /\end{array}$

REGIONS

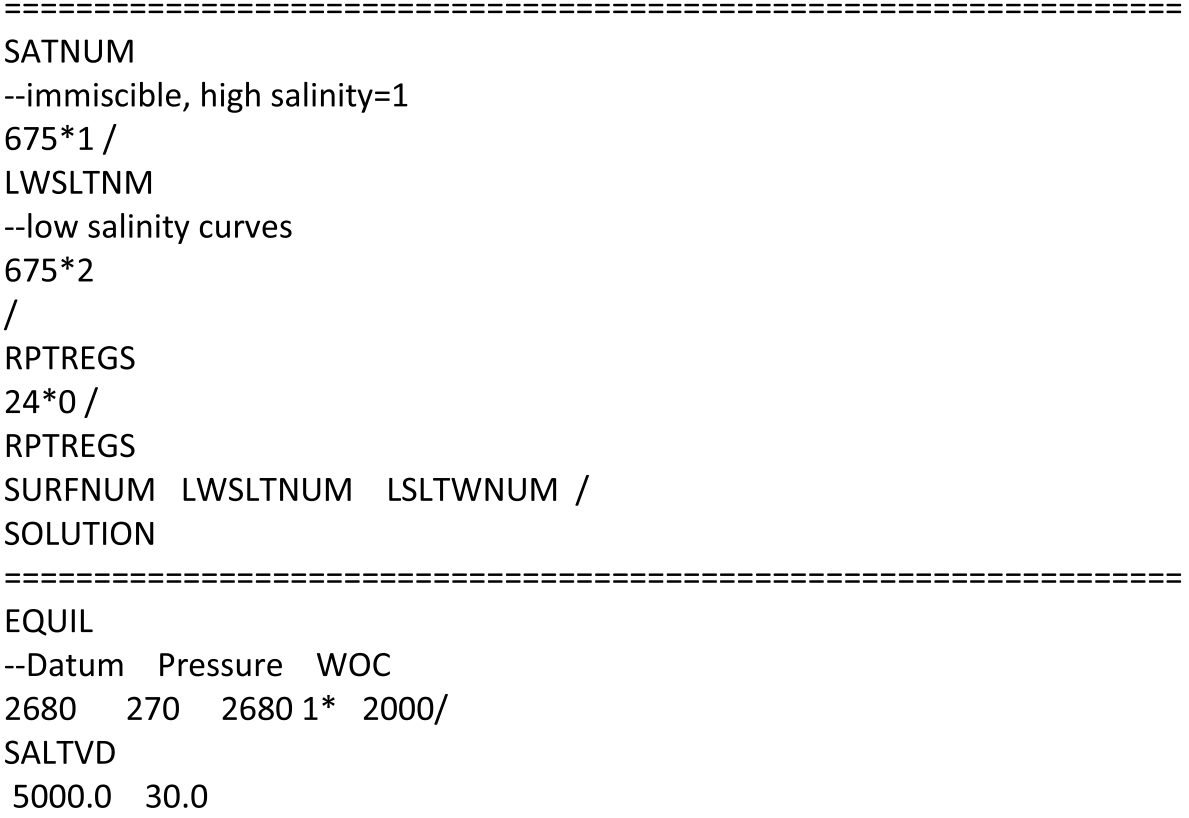




\section{$5500.030 .0 /$ \\ RPTRST \\ 'BASIC=2' / \\ SUMMARY}

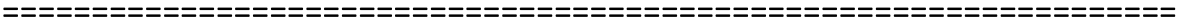

FSPR

FSPT

FSIR

FSIT

FWIR

FOPR

FGPR

FOPT

FPR

FOPV

FWIT

FOE

TCPU

GSPR

'G' /

GSPT

'G' /

GSIR

'G'/

GSIT

'G' /

GSPR

' $G$ '/

WSPR

'OP' I

WSPT

'OP'/

WSIR

'INJ' /

WSIT

'OP' /

WBHP

I

WOPR

'OP' /

WGPR

'OP' I

WLPR

'OP' I 


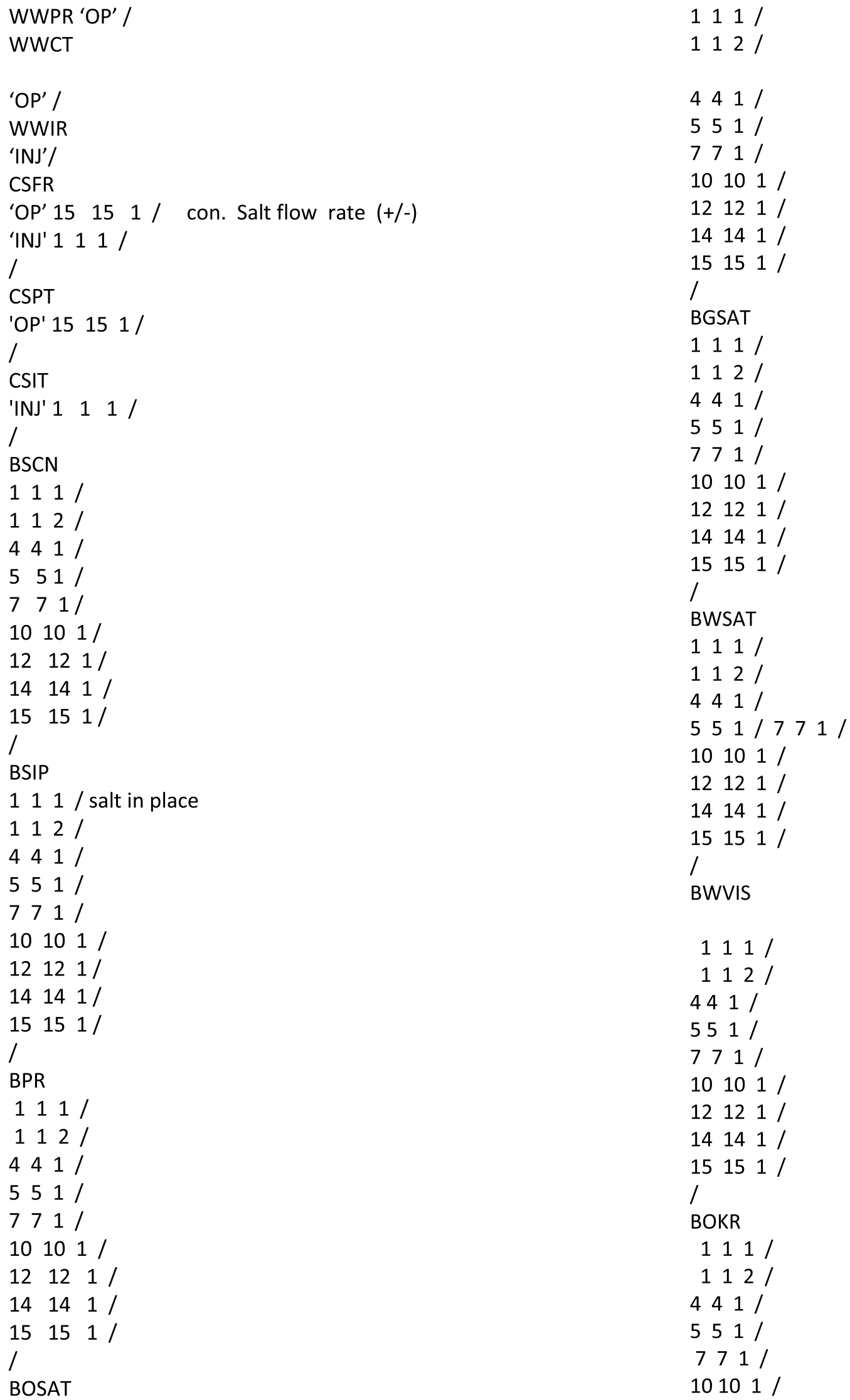




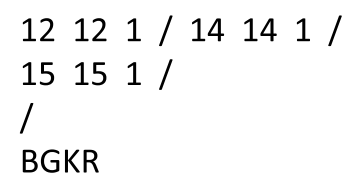

$111 /$

$112 /$

$441 /$

$551 /$

$771 /$

$10101 /$

$12121 /$

$14141 /$

$15151 /$

/

BWKR

111 /

$112 /$

$441 /$

$551 /$

$771 /$

$10101 /$

$12121 /$

$14141 /$

$15151 /$

/

BWKR

$111 /$

$112 /$

$441 /$

$551 /$

$771 /$

$10101 /$

$12121 /$

$14141 /$

$15151 /$

/

FUHCPVI

RPTONLY

ALL

SEPARATE

RUNSUM

MSUMLINS

MSUMNEWT

SCHEDULE

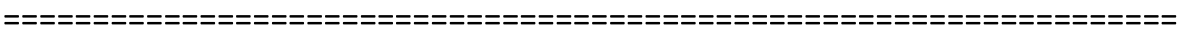

TUNING

$130 /$

/

I

WELSPECS

'OP' ‘G' 15152600 'OIL' / 


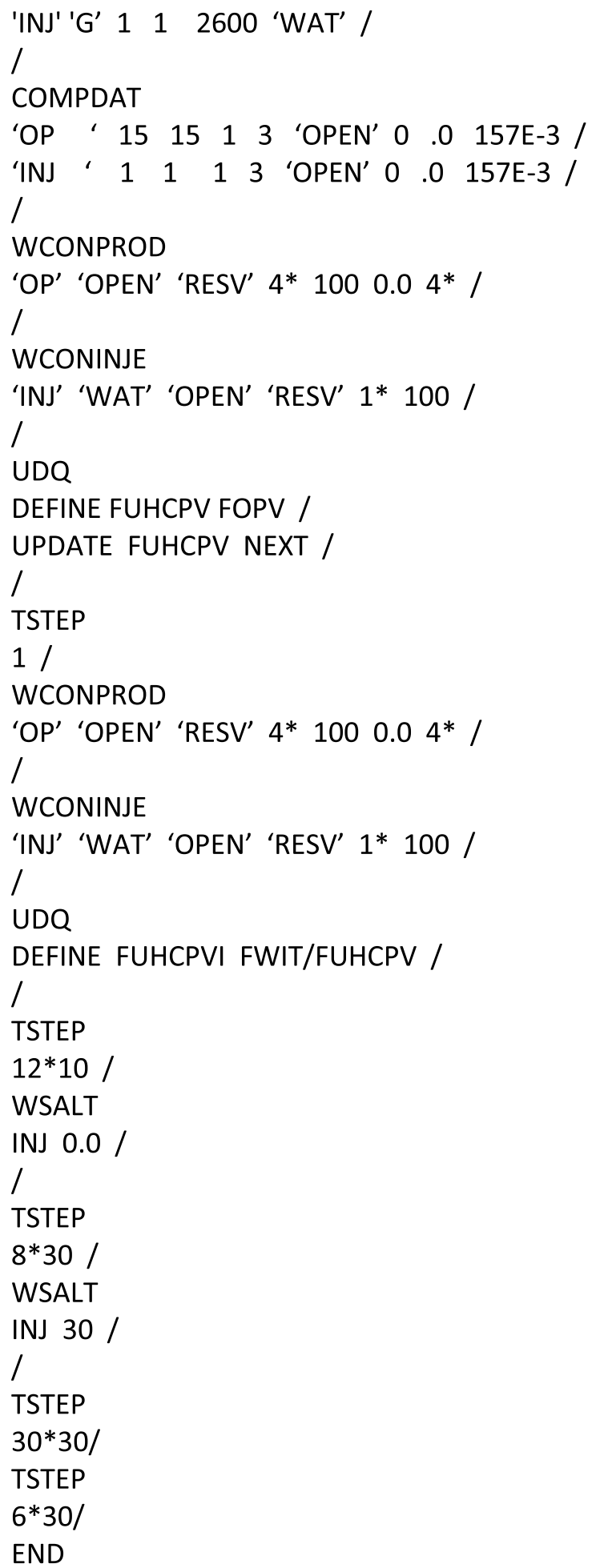

\section{References}

Afzali Tabar M, Rashidi A, Alaei M, Koolivand H, Pourhashem S, Askari S (2020) Hybrid of quantum dots for interfacial tension reduction and reservoir alteration wettability for enhanced oil recovery (EOR). J Mol Liq 307(1):112984. https://doi. org/10.1016/j.molliq.2020.112984

Agbalaka CC, Dandekar AY, Patil SL (2009) Coreflooding studies to evaluate the impact of salinity and wettability on oil recovery efficiency. Transp Porous Media 76(1):77-94

Alben KT (2002) Books, and Software: design, analyze, and optimize with Design-Expert. Anal Chem 74(7):222-223

Amott E (1959) Observations relating to the wettability of porous rock. Trans AIME 219:156-162

Austad T, Shariatpanahi SF, Strand S, Black CJJ (2011) Conditions for a low-salinity enhanced oil recovery (EOR) effect in carbonate oil reservoirs. Energy Fuels 26(1):569-575

Baradari A, Hosseini E, Soltani B, Jadidi N (2020) Experimental investigation of the ionic content effect on wettability alteration in smart water for enhanced oil recovery. Pet Sci Technol 1:11. https://doi.org/10.1080/10916466.2018.1550509

Bernard GG (1967) Effect of floodwater salinity on the recovery of oil from cores containing clays. Society of Petroleum Engineers, In SPE California Regional Meeting

Hosseini E, Chen Zh, Sarmadivaleh M, Mohammadnazar D (2020) Applying low-salinity water to alter wettability in carbonate oil reservoirs: an experimental study. J Petr Explor Product Technol. https://doi.org/10.1007/s13202-020-01015-y

Hosseini E, Hajivand F, Yaghodous A (2018) Experimental investigation of EOR using low-salinity water and nanoparticles in one of the southern oil fields in Iran. Energy Sour Part A Recov Util Environ Eff 40(16):1974-1982. https://doi.org/10.1080/15567 036.2018 .1486923

Kokal S, Al-Kaabi A (2010) Enhanced oil recovery: challenges \& opportunities. Official Publication, World Petroleum Council

Lager A, Webb K, Collins R (2008) LoSal enhanced oil recovery: evidence of enhanced oil recovery at the reservoir scale. Society of Petroleum Engineers, In SPE Symposium on Improved Oil Recovery

McGuire P, Chatham JR, Paskvan FK, Carini FH (2005) Low salinity oil recovery: an exciting new EOR opportunity for Alaska's North Slope. SPE Western regional meeting. Society of petroleum engineers

Pu, H., Xie, X., Yin, P., 2008. Application of coal-bed methane water to oil recovery by low salinity water flooding. In paper SPE 113410 presented at the 2008 SPE improved oil recovery symposium

$\mathrm{Pu}$ H, Xie X, Yin P (2008) Application of coal-bed methane water to oil recovery by low salinity water, flooding. In Paper SPE 113410 presented at the 2008 SPE improved oil recovery symposium

Souraki Y, Hosseini E, Yaghodous A (2019) Wettability alteration of carbonate reservoir rock using amphoteric and cationic surfactants: experimental investigation. Energy Sour Part A Recovery Utilization Environ Effects 41(3):349-359. https://doi. org/10.1080/15567036.2018.1518353

Sun C, McClure JE, Mostaghimi P, Herring AL, Meisenheimer DE, Wildenschild D, Berg S, Armstrong RT (2020) Characterization of wetting using topological principles. J Coll Interf Sci 578:106115. https://doi.org/10.1016/j.jcis.2020.05.076

Taheriotaghsara M, Bonto M, Eftekhari AA, Nick HM (2020) Prediction of oil breakthrough time in modified salinity water flooding in carbonate cores. Fuel 274:117806. https://doi.org/10.1016/j. fuel.2020.117806

Yousef; A.A., Al-Saleh S.H., Al-Kaabi, A. Al-Jawfi. M.S. (2011) Laboratory investigation of the impact of injection-water salinity 
and ionic content on oil recovery from carbonate reservoirs. SPE Reservoir Eval Eng 14(05):578-593

Zahid A, Shapiro A, Stenby EH (2012) Managing injected water composition to improve oil recovery: a case study of North Sea chalk reservoirs. Energy Fuels 26(6):3407-3415

Zhang Y, Morrow NR (2006) Comparison of secondary and tertiary recovery with a change in injection brine composition for crude-oil/sandstone combinations. In SPEIDOE Symposium on improved oil recovery. 2006. Society of petroleum engineers

Publisher's Note Springer Nature remains neutral with regard to jurisdictional claims in published maps and institutional affiliations. 